\title{
Monetary and Fiscal Policy Interactions over the Cycle: Some Empirical Evidence*
}

\author{
V. Anton Muscatelli \\ University of Glasgow and CESifo, Munich \\ Patrizio Tirelli \\ Carmine Trecroci \\ Università Milano-Bicocca Università di Brescia
}

First draft: September 2001

This version: October 2002

\begin{abstract}
This paper estimates VAR models to examine the response of monetary and fiscal policy to macroeconomic targets, and the interdependence between the two policy instruments. The models are estimated for a number of G7 countries. Our findings show that, whilst monetary and fiscal policy are increasingly used as strategic complements, the responsiveness of fiscal policy to the business cycle has decreased since the 1980s. We also demonstrate that shifts in the strategic interdependence between fiscal and monetary policy can be captured using Bayesian VAR models.
\end{abstract}

JEL Codes: E63, E58, E60

\section{Introduction}

The advent of EMU has raised a number of issues regarding the relative roles of fiscal and monetary policy. The Stability and Growth Pact (SGP henceforth) has imposed strict limits to countercyclical fiscal policies. Whilst the SGP is seen as a tool to avoid excessive debt accumulation (see Beetsma and Jensen, 1999; Beetsma and Uhlig, 1997), a number of authors (see Eichengreen and Wyplosz, 1998, for example) fear that the SGP will hamper the operation of automatic stabilizers.

However, there is relatively scarce evidence on the interaction of fiscal and monetary policies. Whilst considerable attention has been given to the

\footnotetext{
*We are grateful to participants at the Conference on 'EMU Macroeconomic Institutions' held in Milan in September 2001, for comments on an earlier draft of this paper, and particularly to Giuseppe de Arcangelis, Roel Beetsma, Alex Cukierman, and Jacques Melitz for helpful comments. We are also grateful to seminar participants at Mainz and Trento. The usual disclaimer applies.
} 
way in which monetary authorities respond to macroeconomic conditions ${ }^{1}$, much less empirical work has been done on fiscal policy ${ }^{2}$. Even less attention has recently been paid to the interdependence between fiscal and monetary policy at the empirical level.

The only notable exception are the studies by Mélitz (1997, 2000), Wyplosz (1999) and von Hagen et al. (2001). For instance, using pooled data for a number of OECD economies, Mélitz (1997) finds that fiscal and monetary policy tend to move in opposite directions to each other ${ }^{3}$. In other words, they are strategic substitutes. He also finds that a higher debt burden tends to trigger an adjustment process.

The present paper extends this work in a number of directions. We use VAR models (both conventional and Bayesian VARs) to characterise fiscal-monetary interactions rather than estimate monetary and fiscal reaction functions using single-equation methods. VAR studies of fiscal policy are relatively scarce. This may be due to the standard criticism that a government change may determine the expectation of a fiscal policy shift well before the new fiscal stance is detected in the VAR (see for example Mountford and Uhlig, 2002). In our view, such a criticism is probably overstated. In fact, one should bear in mind that the specific features of a policy package are crucial in determining agents' reaction to fiscal legislation, whose details often remain uncertain until the legislative process has been completed. Moreover, our results show that the fiscal shocks identified in the VAR do have significant effects, while additional evidence discussed in Muscatelli, Tirelli and Trecroci (2002b) shows that fiscal and monetary shocks play a similar role in explaining the forecast error variance of business cycle fluctuations. The evidence collected in the present paper sheds some light on the dynamic adjustment of output, inflation and monetary policy. This allows us to get a more complete picture of the dynamic interactions (including regime shifts) between these jointly endogenous variables, and to address a number of issues.

First, we examine whether the strategic substitutability result holds for individual OECD countries. Our focus is on some of the major G7 economies, and we estimate VAR models with both fiscal and monetary policy instruments to model the fiscal-monetary interactions. Our findings show that the result of strategic substitutability does not hold uniformly for all countries. Indeed, our results point to some interesting asymmetries in the responses of fiscal and monetary policy. Moreover, our approach enables us to examine the changes over time in the degree of strategic interaction between fiscal and monetary policy, as the relationship between the policy

\footnotetext{
${ }^{1}$ See for example Clarida et al $(1998,2000)$, Muscatelli et al. (2000, 2002a), Favero and Rovelli (1999).

${ }^{2}$ See Blanchard and Perotti (1999) and Fatas and Mihov (2000).

${ }^{3}$ Mèlitz uses a short term money market rate as the monetary instrument and the primary surplus as a percentage of potential output as the fiscal instrument.
} 
instruments may not be constant over time. In a number of countries in our sample the behaviour of monetary policy has changed markedly since the early 1980s, with fiscal policy in Europe becoming increasingly constrained by the process of nominal convergence. The SGP was the final element in this policy shift. Even in the USA, the debt-reduction measures of the 1990s represent a sea change in the conduct of fiscal policy. We thus analyse the extent to which the nature of fiscal-monetary interactions has changed by reporting VAR estimates for the latter part of our sample, and by computing some Bayesian VAR estimates. These show that, in some countries, the linkage between fiscal and monetary policy has shifted over time.

Second, we examine whether Mélitz' result that a high degree of indebtedness triggers an adjustment in fiscal policy is robust for individual countries, and whether it holds at all times. We find no evidence of a deficit feedback on past debt levels, with the exception of Germany.

Third, by using our VAR model of the fiscal-monetary interactions, we see whether, taking account of fiscal policy, we still get a plausible picture of how a) monetary policy reacts to output and inflation shocks; b) output and inflation react to interest rate shocks. As we shall see, our VAR models seem to be broadly consistent with existing studies on monetary policy reaction functions.

Fourth, we examine how fiscal policies react to output and inflation shocks. Theoretical models are unambiguous about how fiscal stabilisation policies operate. Is the empirical evidence consistent with the prescriptions of these theoretical models?

Fifth, we examine how fiscal shocks are transmitted to the economy and whether output and inflation react as expected. We show that some differences emerge between countries, and that in some cases non-Keynesian effects tend to show up (see Giavazzi and Pagano, 1990, 1996).

The rest of this paper is structured as follows. In Section 2 we survey some of the existing literature on monetary-fiscal interactions, and outline some of its key predictions. In Section 3 we outline our empirical methodology. In Section 4 we report and discuss our estimated models. Section 5 concludes.

\section{Models of Fiscal-Monetary Interactions}

The nature of the interdependence between fiscal and monetary policy is a recurring theme in macroeconomics. The traditional analysis focuses on the optimal policy mix when both policy instruments are under the control of a single policymaker who aims at mutually inconsistent targets. In recent years, following the widespread shift to a separation of powers between fiscal authorities and independent central banks, theoretical research has turned to the analysis of fiscal/monetary policy interactions when the two 
policymakers' objectives differ.

An important issue has been whether fiscal discretion should be regarded as a threat to monetary policy commitment. The so-called Fiscal Theory of Price Level Determination rests on the assumption that price stability is unattainable unless intertemporal government solvency is guaranteed. This, in turn, implies that a rise in inflationary pressures calls for both an interest rate rise and the sterilisation of the ensuing higher debt-service payments. Dixit and Lambertini $(2000,2001)$ explore the relation between fiscal discretion and monetary commitment in a model where the central bank has only partial control over inflation, which is also directly affected by the fiscal policy stance ${ }^{4}$. Not surprisingly, these authors find that in this case fiscal discretion destroys monetary commitment. Dixit and Lambertini also show that the tendency towards substitutability emerges when fiscal policy tends to increase both output and inflation, whilst complementarity could emerge where fiscal expansions have non-Keynesian (contractionary) effects on output and inflation.

An intriguing contribution by Hughes Hallett and Viegi (2000) suggests that policy conflict may be endogenous to the choice of central bank preferences: a strong bias in favour of price stability may induce the election of fiscal policymakers who are more concerned about output.

Buti, Roeger and in't Veld (2001) suggest that the specific form of interdependence between fiscal and monetary policies, i.e. the alternative between strategic substitutability and complementarity, should not necessarily be interpreted in terms of conflict or cooperation, and might be shockdependent. In their model the bank targets inflation and a nominal interest rate objective, whereas the fiscal authority pursues output and deficit targets. Supply shocks unambiguously induce conflicting policies, whereas the opposite holds true for demand shocks.

Empirical evidence, uniformly based on panel data analysis, is scarce and loosely related to the theoretical debate. Work by Mélitz (1997, 2000) and Wyplosz (1999) broadly supports the view that the two policies tend to move in opposite directions. By contrast, von Hagen, Hughes-Hallett and Strauch (2001) find that the interdependence between the two policymakers is asymmetric: looser fiscal stances match monetary contractions, whereas monetary policies broadly accommodate fiscal expansions. Finally, from the early nineties these authors detect smaller fiscal responses to both monetary shocks and cyclical conditions.

\footnotetext{
${ }^{4}$ Furthermore, conflicting objectives between the two policymakers, where the central bank tries to achieve output and inflation levels below the fiscal authority's targets, lead to highly suboptimal Nash equilibria where monetary policy is too contractionary and the fiscal stance is insufficiently expansionary.
} 


\section{Empirical Issues and the Econometric Method- ology}

Structural VAR techniques are now a customary tool in the study of monetary policy. They provide a simple and powerful way to describe the dynamic interactions between jointly endogenous variables. In fact, the lags associated with the formulation of budget policies, and those usually thought to characterise the macroeconomic effects of tax and spending decisions, make the VAR framework in principle better suited to analyse the process of fiscal transmission than in the case of monetary policy changes. VARs are particularly attractive in the context of economic policy analysis ${ }^{5}$ because of their ability to encompass the identification of macroeconomic effects of policy decisions and the feedback reaction of policy authorities to the business cycle in a relatively intuitive estimation strategy. Of course, one of the strengths of VAR models (the limited need to rely on identifying restrictions) is also one of its weaknesses. There is no attempt in just-identified VARs to identify policymakers' preferences or to estimate theory-based structural reaction functions. In practice the policy reactions estimated in a VAR model could be interpreted as reduced forms of forward-looking policy reaction functions and structural parameters of the underlying economy. The impulse responses would then be interpreted as responses to unanticipated shocks to the economy. However, we would make two points in this regard. First, in order to estimate structural reaction functions one has to make some restrictive assumptions regarding the specification of the policy rules and impose (or assume) certain identifying restrictions. These modelling assumptions are likely to be controversial, especially as far as fiscal policy rules are concerned, as they are likely to be less robust and stable over time. Second, whilst a VAR does not allow one to focus on individual structural parameters of the policy reaction functions, it does nevertheless allow a general picture to emerge regarding the policy reactions which occurred, especially when the econometric evidence is backed up with reference to well-known policy events or policy regime changes. The estimation of a fully-fledged structural model of fiscal and monetary reaction functions is beyond the scope of this paper and will be considered in further work.

Indeed, as noted above, the use of VAR models to identify fiscal policy shocks and the effects of their transmission is still at a rather embryonic stage $^{6}$, whereas the interplay between fiscal and monetary policy decisions and their macroeconomic effects are yet to be tackled, to our knowledge, in a dynamic, system-based approach.

In this paper we apply two complementary VAR methodologies to a set

\footnotetext{
${ }^{5}$ See Canova (1995) for a survey, and Bernanke and Mihov (1998) for an often-cited application to the analysis of monetary policy.

${ }^{6}$ Blanchard and Perotti (1999), Edelberg, Eichenbaum and Fisher (1998), Fatas and Mihov (2000) are amongst the early contributions to this approach.
} 
of quarterly variables for five OECD countries: Germany, France, Italy, the United Kingdom, and the US. First, we estimate and analyse a conventional structural VAR on a vector comprising the output gap $\left(y_{t}\right)$, the inflation rate $\left(\pi_{t}\right)$, a measure of fiscal stance $\left(g_{t}\right)$ and the call money rate $\left(r_{t}\right)$.

The measure of fiscal stance is constructed as a deviation from a HodrickPrescott filtered trend (setting the HP factor at $\lambda=1600$ ). Other studies (see Melitz, 1997, 2000, Wyplosz, 1999) use the primary deficit. Our choice is motivated by the fact that primary deficit data is only available at low frequencies and would not allow us sufficient observations to estimate our VAR models. It may be argued that, due to the contemporaneous effect of interest rate payments, total deficit measures provide a somewhat blurred picture of the fiscal policymaker's true reactions to the business cycle. However, by filtering the deficit series, we are removing the long-run trend component in the deficit, which is driven by debt interest dynamics. This way, our FPI variable arguably captures short-run fiscal impulses and allows us to analyse countercyclical fiscal policy ${ }^{7}$. On the other hand, we cannot identify the primary deficit response to credibility shocks, which presumably affect the overall deficit through debt service payments. Nevertheless, our analysis of the fiscal response to inflation shocks does provide an indirect test of the fiscal theory of price level determination (see the discussion in the conclusions).

The optimal VAR order was selected according to results from the application of conventional information criteria (AIC, HQ, SC) and formal LR tests; the models we estimated were either $\operatorname{VAR}(2)$ or $\operatorname{VAR}(3)$. The structural parameters were recovered through the imposition of a recursive, Cholesky-type, decomposition of the residual covariance matrix. The variable ordering chosen allows for contemporaneous effects of all variables on the monetary policy instrument, while the fiscal policy indicator is assumed not to react to interest-rate shocks within the quarter. The longest estimation sample starts from the early seventies for the European countries and from the late fifties for the US. Clearly, the use of such a long span in a standard structural VAR approach has to take into account the possibility of structural changes and regime shifts over the sample. This is why we also illustrate estimates from sub-sample periods, in an attempt to capture differences between the last two decades and the preceding years.

Next, we pursue the attempt to identify regime changes further, by computing time-varying VAR estimates. Our approach follows the Bayesian route pioneered by Doan, Litterman and Sims (1984), which allows the parameters of the estimated VAR and of the impulse response function to evolve over time as more observations are added. This feature is particularly useful in our case, as regime shifts that took place over the sample

\footnotetext{
${ }^{7}$ In current work we are extending our investigation to construct quarterly series on the budget deficit - see Muscatelli, Tirelli and Trecroci (2002b).
} 
might have not only modified the parameters of the functions we are about to study, but they might have done so in a gradual manner.

We now sketch the estimation procedure we followed. Let us start with a standard $\operatorname{VAR}(p)$ :

$$
X_{t}=c+\sum_{j=1}^{p} A_{j} X_{t-j}+\varepsilon_{t}
$$

where $X_{t}$ is a $n \times 1$ vector of endogenous variables, $A_{j}$ s are the $n \times n$ matrices of parameter coefficients, and $\varepsilon_{t}$ is a $n \times 1$ vector of disturbances, for which:

$$
E\left\{\varepsilon_{t}\right\}=0 ; E\left\{\varepsilon_{t} \varepsilon_{t}^{\prime}\right\}=\Sigma ; E\left\{\varepsilon_{t} \varepsilon_{s}^{\prime}\right\}=0, \forall t \neq s
$$

In what follows we use the same notation as in Lutkepohl (1991), and Hamilton $(1994)^{8}$. We thus re-write the model in the following way:

$$
\begin{aligned}
X & =A Z+U ; \\
X & =\left(\begin{array}{cccc}
X_{p+1} & X_{p+2} & \ldots & X_{T}
\end{array}\right) \\
A & =\left(\begin{array}{cccc}
c & A_{1} & \ldots & A_{p}
\end{array}\right) ; Z=\left(\begin{array}{llll}
Z_{p} & Z_{p+1} & \ldots & Z_{T-1}
\end{array}\right) \\
Z_{t} & =\left(\begin{array}{c}
1 \\
X_{t-1} \\
X_{t-2} \\
\vdots \\
X_{t-p}
\end{array}\right)
\end{aligned}
$$

Assuming time-varying coefficients, equation $j$ from the system in (1) can be written as

$$
x_{t, j}=\mathbf{Z}^{\prime}\left(\begin{array}{l}
c_{j} \\
\beta_{j 1}^{1} \\
\vdots \\
\beta_{j n}^{1} \\
\vdots \\
\beta_{j 1}^{p} \\
\vdots \\
\beta_{j n}^{p}
\end{array}\right)+\varepsilon_{t, j}=\mathbf{Z}^{\prime} \boldsymbol{\beta}_{t}+\varepsilon_{t, j}
$$

\footnotetext{
${ }^{8}$ See also Kim and Nelson (1999).
} 
where the $\beta_{t}$ s are the elements of the VAR coefficients.

Doan et al. (1984) postulate a Bayesian prior distribution for the firstperiod value of the coefficient vector: $\boldsymbol{\beta}_{11} \sim N\left(\overline{\boldsymbol{\beta}}, \mathbf{P}_{1 \mid 0}\right)$. The procedure we follow assumes that the VAR coefficients follow an $\operatorname{AR}(1)$ process; the transition equation of the system is therefore:

$$
\boldsymbol{\beta}_{1 t}=\left(1-\psi_{1}\right) \overline{\boldsymbol{\beta}}+\psi_{1} \boldsymbol{\beta}_{1 t-1}+\boldsymbol{\xi}_{1 t}
$$

In the above equation, the parameter vector follows a simple autoregressive process, in which the weighting parameter $\psi_{1}$ determines the importance of the steady-state value for the coefficient vector. The disturbance term is uncorrelated with the disturbances in the original VAR: $\operatorname{cov}\left(\boldsymbol{\xi}_{1 t}, \varepsilon_{1 t}\right)=0$, whereas the expected value $\overline{\boldsymbol{\beta}}$ consists of a vector of zeroes with one as elements corresponding to the own variable at lag $1\left(z_{1, t-1}\right)$ for each equation. This prior holds that changes in the endogenous variable modelled are so difficult to forecast that the coefficient on its lagged value is likely to be near unity, while all other coefficients are assumed to be near zero. The prior distribution is independent across coefficients, so that the MSE of the state vector is a diagonal matrix.

The matrix $\mathbf{P}_{1 \mid 0}$ is given by:

$$
\mathbf{P}_{1 \mid 0}=\left(\begin{array}{ll}
\vartheta \widehat{\tau}_{1}^{2} & \mathbf{0}^{\prime} \\
\mathbf{0} & (\mathbf{G} \otimes \mathbf{C})
\end{array}\right)
$$

where

$$
\begin{aligned}
& \mathbf{G}=\left(\begin{array}{lllll}
\gamma^{2} & 0 & 0 & \ldots & 0 \\
0 & \gamma^{2} / 2 & 0 & \ldots & 0 \\
0 & 0 & \gamma^{2} / 3 & \ldots & 0 \\
\vdots & \vdots & \vdots & \ldots & \vdots \\
0 & 0 & 0 & \ldots & \gamma^{2} / n
\end{array}\right) \\
& \mathbf{C}=\left(\begin{array}{llllll}
1 & 0 & 0 & & \ldots & 0 \\
0 & w^{2} \widehat{\tau}_{1}^{2} / \widehat{\tau}_{2}^{2} & 0 & \ldots & 0 \\
0 & 0 & w^{2} \widehat{\tau}_{1}^{2} / \widehat{\tau}_{3}^{2} & \ldots & 0 \\
\vdots & \vdots & \vdots & & \ldots & \vdots \\
0 & 0 & 0 & & \ldots & w^{2} \widehat{\tau}_{1}^{2} / \widehat{\tau}_{k}^{2}
\end{array}\right)
\end{aligned}
$$

$\mathbf{Q}$, the covariance matrix of $\boldsymbol{\xi}_{1 t}$, is given by: $\mathbf{Q}=\psi_{2} \mathbf{P}_{1 \mid 0}$.

Doan et al. (1984) suggest the use of a predefined set of values for the above parameters. The following assumptions are made: $\gamma^{2}=0.07, w^{2}=$ 
$1 / 74, \vartheta=630, \psi_{1}=0.999, \psi_{2}=10^{-7}$. In addition, $\widehat{\tau}_{i}^{2}$ is the estimated variance of the residuals for a univariate $\mathrm{AR}(\mathrm{n})$ regression estimated for series $i$. Note that the assumption is that the coefficient vector $\boldsymbol{\beta}$ converges only very slowly towards the mean. The factor $\gamma$ defines the analyst's confidence that the first-order autoregressive coefficients $\beta_{i i}^{1}$ relating $z_{i t}$ to $z_{i t-1}$, is near unity for all $i ; \vartheta$ is set sufficiently large to ensure that the prior expectation that the constant term is zero is given little weight; $w^{2}$ is set low to ensure that lags of other variables $z_{j t}(j \neq i)$ are less useful in forecasting $z_{i t}$ than own-lags. Doan et al. find that these values work well for typical time series.

This general time-varying estimation problem is solved by forecasting in each period the optimal state vector based on information available up to the previous period. Under the normality and independence assumptions about the disturbances, the computation of the state vector is simply obtained by applying the Kalman filter (Harvey, 1989; Hamilton, 1994). This allows us to obtain filtered estimates of the VAR parameters and residual variance-covariance matrix, for each observation in the sample. Orthogonalised impulse responses are finally computed according to the standard Cholesky decomposition, generating a set of different impulse responses for each observation of our sample.

\section{Results}

\subsection{Standard SVAR, Full Sample Estimates}

The analysis carried out in this paper focuses on impulse response functions ${ }^{9}$. Figures 1-5 show 95\% confidence bands for the impulse responses computed from our structural VAR model estimated over the full sample. Turning first to the strategic complementarity/substitutability issue, we see that the form of interdependence between the two instruments is asymmetric and differs across countries. In the US and the UK interest rates fall significantly in the first quarter after the fiscal expansionary shock. In the cases of Italy, Germany and France there seems to be no clear monetary reaction, although in Germany there are some signs that monetary policy tends to offset fiscal policy shocks, as the impulse responses are nearly significant.

In contrast, fiscal policy tends to be a strategic substitute for monetary policy, with the exception of a temporary complementarity in the case of Germany and the US after 1-2 quarters, subsequently reversed in the medium run. In the case of the UK the fiscal policy response is not significant.

\footnotetext{
${ }^{9}$ The decomposition of the forecast error variance of output gap shocks confirms, among other things, that a large role is played by both fiscal and monetary policies. This result and additional evidence as to the relative importance of economic policy innovations in the stabilisation of macroeconomic fluctuations are discussed in a companion paper (Muscatelli, Tirelli and Trecroci, 2002b).
} 
We turn next to how the policy instruments react to the output gap and inflation. The monetary policy reactions to the inflation and output gap shocks have the predicted signs. In all cases interest rates respond positively to the inflation and output gap shocks, although there is a difference in the quantitative response, as one might expect from existing evidence on monetary reaction functions (see Rudebusch and Svensson, 1999). In general, the response is stronger in countries like the US and Germany ${ }^{10}$.

We find evidence of the usual price puzzle immediately following an interest rate shock ${ }^{11}$. By contrast, the interest rate shock triggers a fall in the output gap. This evidence shows that the introduction of fiscal variables does not yield markedly different conclusions from the conventional VAR analysis conducted in terms of monetary policy only.

Fiscal policy reacts as expected to output gap shocks: the deficit falls after a short lag. In the UK and the US the fiscal policy response is quantitatively larger than in France, Italy and Germany. The evidence on countercyclical responses to inflation is weaker and far less uniform (significant countercyclical responses are observed only in the US and France). This mixed evidence on the response to inflation can be rationalised by assuming that fiscal responses are mostly driven by automatic stabilisers, which are triggered when output fluctuates, and much less so in the face of inflation shocks.

Fiscal shocks seem to have a standard expansionary impact on output in the case of the USA, and to a lesser extent the UK (the impulse response function is not significant in the latter case). Negative (non-Keynesian) impacts on the output gap are evident for other countries after 5-9 quarters, although these effects are not significant. The only exception is Germany at even longer horizons, where the impulse response function is almost significant at the $5 \%$ level. The impact of fiscal shocks on inflation, more conventionally Keynesian, is only significant in the case of Germany and, in the longer run, of the US.

\subsection{Robustness Checks: Identification and Non-Linearities}

Although our impulse responses were obtained with a Cholesky decomposition, in fact the ordering seems to matter little to the results, which are reasonably robust. In fact, we computed some generalised impulse responses for the above VAR estimates (see Koop et al., 1996) and obtained very similar response dynamics. These illustrate that the residual variance-covariance matrix is close to being diagonal, and orthogonalisation using a Cholesky

\footnotetext{
${ }^{10} \mathrm{It}$ should be recalled that these are full-sample estimates, and therefore include the somewhat more accommodating monetary policies implemented before 1980 (see Clarida et al, 1998, 1999; Muscatelli et al. 2002).

${ }^{11}$ The price puzzle could be removed by introducing a commodity price index, but this reduces our available sample considerably and affects the significance of our results.
} 
decomposition does not produce markedly different results. In addition, we estimated the VAR models imposing a different ordering for the monetary and fiscal policy instruments where the short-term interest rate comes before the budget deficit - though both always follow output and inflation. Our results were broadly confirmed ${ }^{12}$. Hence in what follows we continue to present and discuss results obtained using the Cholesky decompositions with the ordering discussed in Section 3.

Another, more subtle point ${ }^{13}$, concerns the possibility that the contemporaneous response of the deficit to a unit shock in the short-term interest rates may be different from zero, in contrast to what is assumed with a standard recursive triangularisation of the disturbance matrix. For instance, in the case of Italy, where outstanding debt has generally been high and mainly short term, one might expect any change in the level of interest rates to have an immediate impact on debt service payments and hence on overall budget deficits. To check for this, we imposed several non-zero values for the contemporaneous reaction of Italian deficits to a $1 \%$ shock to interest rates. As shown in Figure 6, even assuming an $8 \%$ immediate increase in the budget deficit, the conclusions we have drawn in the former section remain broadly unscathed. In detail, most impulse responses seem to gain some significance, without changing sign. Monetary policy responses to fiscal policy shocks appear almost significant (with a 5 to 6-quarter lag) and pulling in the same direction, whereas interest rates look slightly more effective in stabilising the cycle than before. The first finding is more evident when the model is estimated over the last two decades, whereas the second is more typically found over the 1970s-1980s sample.

Finally, we tested for the possibility of non-linear behaviour by the monetary and fiscal policy authorities. In particular, following Granger and Terasvirta (1993) we fitted the following models for the estimated residuals $\widehat{\varepsilon_{t}}$ of each policy function:

$$
\widehat{\varepsilon_{t}}=\gamma_{0}^{\prime} \mathbf{v}_{t}+\gamma_{1}^{\prime} \mathbf{v}_{t} z_{t}+\gamma_{2}^{\prime} \mathbf{v}_{t}\left(z_{t}\right)^{2}+\gamma_{3}^{\prime} \mathbf{v}_{t}\left(z_{t}\right)^{3}
$$

where $\mathbf{v}_{t}$ is the vector of the variables (except the policy instrument at hand) entering the original VAR models, and $z_{t}$ is a transition variable that is assumed to be in turn either one of the other variables in the VAR model (output gap, inflation, the other policy instrument) or the lagged value of the instrument itself. The results of the tests for the Italian case, which prima facie is the most likely to be characterised by non-linearities in the behaviour of policy authorities, are displayed in Table 1 below. These findings do show some signs of non-linear behaviour in the model, though the evidence is not clear-cut. Note from Table 2 that the null hypothesis $\gamma_{1}=0$ may be picking up some heteroscedasticity due to multiplicative terms in the regressors. The

\footnotetext{
${ }^{12}$ The full results are available from the authors upon request.

${ }^{13}$ We thank G. De Arcangelis for raising this point.
} 
most relevant test of non-linear policy responses is $\gamma_{1}=\gamma_{2}=0$, which picks up whether there is a policy response that depends in a non-linear way on the transition variable. This hypothesis is rejected at the $5 \%$ level only for the fiscal response, and even then the non-linearity is in terms of the lagged budget deficit, which suggests that the non-linearity is unlikely to affect any inference about the responses of fiscal policy to monetary shocks and vice-versa.

\begin{tabular}{cccc}
\hline \hline & Transition Variable & \multicolumn{2}{c}{ Hypothesis Testing } \\
\hline Policies & & $\mathbf{H}_{0}: \boldsymbol{\gamma}_{1}=0$ & $\mathbf{H}_{0}: \boldsymbol{\gamma}_{1}=\boldsymbol{\gamma}_{2}=0$ \\
\hline monetary & $z_{t}=y_{t}$ & 1.2985 & $2.1442^{*}$ \\
& $z_{t}=\pi_{t}$ & 1.1656 & $1.9218^{*}$ \\
& $z_{t}=r_{t-1}$ & 0.6674 & 0.7605 \\
& $z_{t}=b d_{t}$ & $2.8207^{* *}$ & 1.8046 \\
\hline fiscal & $z_{t}=y_{t}$ & 0.4528 & 0.3139 \\
& $z_{t}=\pi_{t}$ & 1.3712 & 0.7273 \\
& $z_{t}=r_{t}$ & $2.4969^{*}$ & 1.6111 \\
& $z_{t}=b d_{t-1}$ & 1.3807 & $4.5129^{* * *}$ \\
\hline \hline
\end{tabular}

Table 1. Italy, Tests of Non-linear Policy Responses.

Notes. The test $\boldsymbol{\gamma}_{1}=\mathbf{0}$ is distributed as a $F(3,94)$ variate under $\mathbf{H}_{0}$; the test $\gamma_{1}=\gamma_{2}=\mathbf{0}$ is instead distributed as a $F(6,94)$ variate under $\mathbf{H}_{0}$. "***", "**", and "*" indicate that the null is rejected, respectively, at the $1 \%, 5 \%$, and $10 \%$ significance level.

Moreover, we should point out that these tests for non-linearity are very general: they do not specify a precise form for the non-linear reaction under the alternative hypothesis. In other words, even when non-linear effects are detected, no obvious operational conclusion can be drawn about the features of the models we estimate. Given that the statistical test we implement has power against different kinds of non-linear models, and that its results do not unambiguously point to non-linearity, this lends support to our view that a linear model provides a useful characterisation of reality.

\subsection{Sub-Sample Estimates}

In this section we divide our full sample into two sub-periods, pre- and post1980. The choice of the sub-samples is suggested by the break in monetary policy stance which was experienced by all these countries in the late 1970s or early 1980s (see Clarida et al., 1998). Thus, for the US we consider a break around 1979Q4, which is usually seen as the point after which the Fed took a more decisive stance on inflation control. For the EU countries we break the sample around 1980-1981, with the exception of Italy. In 19811982 there were major reforms in Italy, separating the functions of the fiscal and monetary authorities and the operations of the Bank of Italy. The 
breakpoint is therefore set at 1982Q4. In the case of France, and Italy, the post-1983 period was then characterised by a gradual hardening of the ERM. In the UK, the post-1981/82 period sees an end to the strict monetarist experiment, and the adoption of a more eclectic monetary policy regime ${ }^{14}$.

We first look again at the complementarity/substitutability issue. Table 2 summarises the results for the two sub-samples, fully presented in Figures 7 to 11 . A (+) or (-) indicates respectively significant evidence of complementarity or substitutability in the reaction of the fiscal or monetary policy instrument to a shock in the other instrument ${ }^{15}$. A (0) indicates that there is no significant response detected from the impulse response function. A double sign indicates a non-monotonic response; i.e. +/- shows that there is complementarity after an initial lag, then followed by substitutability

\section{Table 2: Complementarity/Substitutability in Fiscal and Monetary Policy}

Fiscal Policy Reaction to Monetary Policy Shock

\begin{tabular}{c|c|c} 
Country & pre-1980 & post-1980 \\
\hline USA & $+/-$ & 0 \\
\hline UK & 0 & - \\
\hline Germany & - & + \\
\hline France & + & - \\
\hline Italy & - & 0
\end{tabular}

Monetary Policy Reaction to Fiscal Policy Shock

\begin{tabular}{c|c|c} 
Country & pre-1980 & post-1980 \\
\hline USA & + & + \\
\hline UK & 0 & + \\
\hline Germany & + & 0 \\
\hline France & 0 & + \\
\hline Italy & 0 & +
\end{tabular}

There are a number of points to note from Table 2. There is strong evidence that post-1980 monetary policy is used as a complement to fiscal shocks, with the notable exception of Germany. In contrast, the evidence on fiscal policy is ambiguous. In Germany post-1980 there is a reversal to complementarity, whilst the opposite happened in the UK and France. In the case of Italy, the insignificant result for the 1980s might be explained by a fiscal strategy which was decoupled from the business cycle, both during the apparently unstoppable fiscal expansion of the '80s and during the subsequent contraction in the 1990s. Our post-1980 estimates of the reaction

\footnotetext{
${ }^{14}$ Although further policy breaks were to follow - e.g. the UK's entry to the ERM in 1990, its exit in 1992 (followed by the adoption of inflation targets), and the granting of instrument independence to the Bank of England in 1997.

${ }^{15}$ Thus, for instance, the (-) in the case of the fiscal reaction to monetary policy in France in the post-1980 results shows that FPI reacted with an expansion to an increase in the interest rate (i.e. a monetary contraction).
} 
of fiscal policy to monetary policy correspond then to the results of Mélitz (1997, 2000), and more closely to those of von Hagen et al ${ }^{16}$ (2001), who find that fiscal policy has become less sensitive to the business cycle, in line with the process of nominal convergence and the imposition of the Maastricht criteria.

Turning to Figures 7-11 we find little evidence in favour of Dixit and Lambertini $(2000,2001)$ argument that the relationship between the two policy instruments depends on the sign of the fiscal impact on inflation and output. In fact, fiscal policy does not appear to have a very significant impact on output and inflation. Even ignoring the significance of the impulse responses, we noted above that there is a tendency for more conventional Keynesian effects of fiscal policy in the UK and US and negative impacts on output in the other countries (particularly Italy and Germany post-1980). Whilst this might explain why monetary policy has become more complementary to fiscal policy post-1980 in Italy and France, it is difficult to tationalise the pattern in the other countries. In our view, a more consistent explanation is that a conventional Keynesian reaction to the output cycle seems the main driving factor behind fiscal policies, with a decreasing importance over time in Germany and Italy.

\subsection{Debt Dynamics and Fiscal Policy}

We have also experimented with extensions to our VAR analysis to include debt adjustment. The purpose of this was to identify any feedback between the deficit and debt to GDP ratio ${ }^{17}$. We thus examined whether nominal debt and nominal GDP were cointegrated for the countries in our sample. Our results were generally disappointing. Cointegration was not found for any of the countries with the exception of Germany, where there was some evidence of feedback from the debt/GDP ratio to fiscal policy. To some extent this is not entirely surprising, as the sample period includes periods over which the nominal debt/GDP ratio was trending in a number of countries, and these countries were not targeting a particular value of the debt/GDP ratio. These results are not reported here for reasons of space, but in further work we intend to explore whether the feedback effect can be detected over sub-samples.

\subsection{Bayesian VAR Estimates}

In this section we reconsider the issue of policy shifts, i. e. changes in the nature of the interdependence between the two policy instruments. Simple

\footnotetext{
${ }^{16}$ Recall that von Hagen et al. (2001) find that whilst monetary contractions lead to fiscal policy expansions, fiscal expansions are accommodated by monetary policy over the sample period 1973-89.

${ }^{17}$ As discussed in the policy design context by Leith and Wren-Lewis (2000) and detected in empirical work by Melitz (1997).
} 
sub-sample estimates are a rough-and-ready indicator, whereas Bayesian estimates allow us to get far deeper insights. In fact we find that some of the conclusions we reached in the former section must be at least qualified.

To illustrate how the Bayesian VAR analysis can capture shifts in the VAR's parameters, in Figure 12 we analyse the French fiscal policy response to a shock in the output gap, showing four observations: 1985Q1, 1988Q1, 1990Q1 and 1996Q1. This exercise gives some intuition on how the working of automatic stabilizers and discretionary fiscal policy has varied over time. In 1985 and 1988 we detect an inverse response of the budget deficit to the output shock. However, since 1990 fiscal policy seems to have turned pro-cyclical. Such a shift could not be detected in the post 1980 impulse response functions depicted in Fig. 6.

For reasons of space, we focus only on some episodes where there appear to have been clear policy shifts in the relationship between fiscal and monetary policy. Figures 13 to 16 show some of these episodes. In Figure 13 we show Bayesian VAR estimates for the response of fiscal policy to a unit shock in the monetary instrument in France. Recall that Table 2 suggested that post-1983, French fiscal policy had acted as complement to fiscal policy. Figure 13 confirms this pattern, but provides a richer and more detailed picture. From the graphs, it is apparent that monetary policy was complement to fiscal policy in the 1980s, but became much less so post 1985, as the hard-ERM regime took hold. Indeed, there is clear-cut evidence that since 1995 monetary policy has again become a strategic substitute for fiscal policy. This evolution is confirmed by the estimates for four individual years: 1985, 1988, 1993 and 1997, which show the turning point.

Turning next to Italy, in Figure 14 we show the fiscal policy reaction to monetary policy shocks. In Table 2 we had shown that this had become insignificant post-1983. Again, we see that a richer picture emerges. Up until the mid-1990s fiscal policy had reacted to interest rate increases with an expansion, with a lag of 7-8 quarters (i.e. fiscal policy was a strategic substitute, as reported in Table 2). However, we detect a gradual policy change in the 1990 s, i.e. the fiscal expansion becomes less and less significant, confirming a conventional wisdom about what happened during the transition to EMU.

Figure 15 shows some results concerning the reaction of monetary policy to fiscal shocks in the UK. Post-1982 we had detected a strategic complementarity. However, the detailed impulse responses for 1981, 1985, 1992 and 1998 show that such a complementarity ${ }^{18}$ is only significant in the 1990 s.

Finally, Figure 16 shows some estimates for the US ${ }^{19}$. In the ' 60 s the complementary response of monetary policy to a fiscal shock was barely

\footnotetext{
${ }^{18}$ Other Bayesian VAR estimates, not reported here for reasons of space, show that fiscal policy has become more complementary to monetary policy in the 1990s.

${ }^{19}$ We also found that the fiscal responses to monetary policy were not significant confirming the post-1980 results reported in Table 2 .
} 
significant. From the mid-1970s onwards, however, monetary policy appears to complement fiscal policy, again confirming our earlier results.

In the case of Germany, our Bayesian VAR estimates did not capture any significant shifts in policy, despite the shifts detected by dividing the samples into two sub-samples in the VARs reported in Table 2. The most likely explanation for this is that the major policy changes in Germany came before or around 1980. Our Bayesian VAR estimates require a number of observations to initialise the estimation, and significant effects can be detected only after 1980. It appears that after this date little has changed in German policy.

\section{Conclusions}

The empirical analysis of the interdependence between monetary and fiscal policies, and of their interactions with key macroeconomic variables is a largely unexplored field. This happens despite the growing number of theoretical models that emphasize the role of fiscal rules in influencing monetary policy conduct and affecting business cycle fluctuations. To some extent, our findings are reassuring: the conventional wisdom on the transmission of monetary policy, received from traditional SVAR models, survives to the introduction of a fiscal policy variable. On the other hand, we find that the output effects of fiscal shocks are ambiguous, that fiscal responses to inflation shocks are difficult to detect, and that the nature of interdependence between the two policy variables is highly unstable. None of these results is easily reconciled with popular models designed to explain fiscal policy rules. Moreover, our results indicate also that the fiscal deficit does not react significantly to an inflationary shock. This in turn implies the absence of fiscal dominance, as the fiscal authorities are willing to sterilise the increased debt service from the monetary response to the inflation shock.

Future work should extend Bayesian VAR estimates to model the evolving features of the deficit feedback onto past debt levels. It would also be useful to characterise more precisely shifts in policy regimes, to identify the fundamental driving forces behind the shifts in the interdependence between fiscal and monetary policy. This would enable us to test Buti et al.'s (2001) hypothesis that the nature of the interdependence between fiscal and monetary policies depends on the nature of the shocks hitting the economy.

Finally, our models have focused on monetary and fiscal policy reactions to unanticipated policy shocks. A natural extension to this paper is to focus on quarterly measures of primary fiscal deficits and the systematic interactions between structural fiscal and monetary rules. This would allows us to analyse the extent of monetary-fiscal complementarity-substitutability in response to aggregate demand and supply shocks, which is the subject of further work (see Muscatelli, Tirelli and Trecroci, 2002). 


\section{References}

Alesina, A., Tabellini, G., 1987. "Rules and Discretion with Noncoordinated Monetary and Fiscal Policies". Economic Inquiry 25(4), 619-630.

Beetsma, R.M.W.J., Bovenberg, A.L., 1998. "Monetary Union without Fiscal Coordination May Discipline Policymakers". Journal of International Economics 45, 239-258.

Beetsma, R.M.W.J., and H. Jensen, 1999. "Optimal Inflation Targets, 'Conservative' Central Banks, and Linear Inflation Contracts: Comment". American Economic Review, 89, 342-347.

Beetsma, R.M.W.J., Uhlig, H., 1997. "An Analysisis of the Stability and Growth Pact," Economic Journal 109, 546-71.

Bernanke, B.S. and I. Mihov, 1998. "Measuring Monetary Policy". Quarterly Journal of Economics, 113, 3, pp. 869-902.

Blanchard, O.J., and R. Perotti, 2000. "An empirical characterization of the dynamic effects of changes in government spending and taxes on output". Working Paper, http://econ-www.mit.edu/faculty/blanchar/papers.htm.

Buti, M., Roeger W. and in't Veld 2001. "Stabilising Output and Inflation in EMU: Policy Conflicts and Cooperation under the Stability Pact". Journal of Common Market Studies, forthcoming.

Canova, F., 1995. "Vector autoregressive models: specification, estimation, inference and forecasting." In Pesaran, M.H., and M. Wickens (eds.) (1995). Handbook of applied econometrics: Macroeconomics. Blackwell, Oxford.

Canzoneri, M.B., Cumby R.E., Diba B.T., 1998. "Is the Price Level Determined by the Needs of Fiscal Solvency?" NBER Working Paper No.6471.

Clarida, R., J. Gali, and M. Gertler, 1998. "Monetary policy rules in practice: some international evidence". European Economic Review, vol. 42, no. 6, pp. 1033-1067.

Clarida, R., J. Gali, and M. Gertler, 1999. "The Science of monetary Policy: a New Keynesian Perspective". NBER Working Paper \#7147.

Dixit, A., Lambertini, L., 2000. "Fiscal Discretion Destroys Monetary Commitment". Working Paper, Princeton and UCLA.

Dixit, A., Lambertini, L., 2001. "Monetary-Fiscal Policy Interactions and Commitment Versus Discretion in a Monetary Union". Working Paper, Princeton and UCLA.

Doan, T., R. Litterman and C. Sims, 1984. "Forecasting and conditional projections using realist priori distributions". Econometric Reviews, 3(1), $1-100$.

Edelberg, W., M. Eichenbaum, and J.D.M. Fisher, 1998. "Understanding the effects of a shock to government purchases". NBER Working Paper \#6737.

Eichengreen, B., and C. Wyplosz, 1998. "The Stability Pact: More than a Minor Nuisance?". Economic Policy: A European Forum, April 1998, v. 
0, iss. 26, pp. 65-104.

Fatas, A., and I. Mihov, 2000. "Fiscal policy and business cycles: an empirical investigation. Mimeo, INSEAD.

Favero, C.A., and R. Rovelli, 1999. "Modelling and Identifying Central Banks' Preferences". Centre for Economic Policy Research Discussion Paper \#2178.

Giavazzi, F., and M. Pagano, 1990. "Can Severe Fiscal Contractions Be Expansionary? Tales of Two Small European Countries". NBER Macroeconomics Annual 1990, pp. 75-111. Cambridge, Mass. and London: MIT Press

Giavazzi, F., and M. Pagano, 1996. "Non-Keynesian Effects of Fiscal Policy Changes: International Evidence and the Swedish Experience". Swedish Economic Policy Review, v. 3, iss. 1, pp. 67-103.

Giavazzi, F., T. Jappelli, and M. Pagano, 2000. "Searching for Nonlinear Effects of Fiscal Policy: Evidence from Industrial and Developing Countries". European Economic Review, June 2000, v. 44, iss. 7, pp. 125989.

Granger, C.W.J., and T. Terasvirta (1993). Modelling non-linear economic relationships. Oxford University Press, Oxford.

Hamilton, J., 1994. Time Series Analysis. Princeton University Press, Princeton.

Harvey, A.C., 1989. Forecasting, structural time series models and the Kalman filter. Cambridge University Press, Cambridge.

HM Treasury (2000). "UK Policy co-ordination: The importance of institutional design." Available at http://www.hm-treasury.gov.uk/

Hughes Hallet, A., and N. Viegi, 2000. "Central Bank Independence, Political Uncertainty, and the Assignment of Instruments to Targets". Mimeo, University of Strathclyde.

Kim, C.-J. and C.R. Nelson, 1999. State-space models with regime switching. MIT Press, Cambridge Mass.

Koop, G., M.H. Pesaran, and S.M. Potter, 1996. "Impulse Response Analysis in Nonlinear Multivariate Models". Journal of Econometrics, 74, 119-147.

Leith, C., and S. Wren-Lewis, 2000. "Interactions between monetary and fiscal policy rules". The Economic Journal, 110, C93-C108.

Lutkepohl, H. , 1991. Introduction to multiple time series analysis. Springer Verlag, New York.

Mélitz, J., 1997. "Some Cross-Country Evidence about Debt, Deficits, and the Behaviour of Monetary and Fiscal Authorities". CEPR Discussion Paper No.1653.

Mélitz, J., 2000. "Some Cross-Country Evidence about Fiscal Policy Behaviour and Consequences for EMU", mimeo.

Mountford, A. and Uhlig, H. (2002) "What are the effects of fiscal policy shocks?". Mimeo. 
Muscatelli, A., and C. Trecroci, 2000. "Monetary Policy Rules, Policy Preferences, and Uncertainty: Recent Empirical Evidence." Journal of Economic Surveys, 14:5, pp. 597-627.

Muscatelli, A., P. Tirelli and C. Trecroci, 2002a. "Does institutional change really matter? Inflation targets, central bank reform and interest rate policy in the OECD countries". The Manchester School, vol. 70 (4), 2002.

Muscatelli, A., P. Tirelli and C. Trecroci, 2002b. "Monetary and Fiscal Policy Interactions: Evidence Using Structural New Keynesian Models". Mimeo, University of Glasgow.

Rudebusch, G.D. and L.E.O. Svensson, 1999. "Policy rules for inflation targeting." In Taylor, J.B. (ed.) (1999). Monetary Policy Rules. University of Chicago Press.

von Hagen, J., Hughes Hallett, Strauch, R., 2001. "Budgetary Consolidation in EMU". Economic Papers No. 148. March 2001. European Commission. Brussels.

Woodward, B., 2000. Maestro: Greenspan's Fed and the American Boom. New York: Simon and Schuster.

Wyplosz, C., 1999. "Economic Policy Coordination in EMU: Strategies and Institutions". ZEI Policy Paper B11. 


\section{Data Appendix}

The data employed were quarterly observations, seasonally adjusted where available. The output gap is defined as the (log) difference between actual and potential output. Inflation is the 4-quarter (log) difference in the Consumer Price Index and, in the US case, in the GDP price index. The monetary policy instrument considered was the Fed Funds Rate for the US, and the respective call money rate for all other countries. The fiscal policy indicator was the total budget deficit, i.e., the difference between government current expenditures (consumption + investment) and tax receipts. A Hodrick-Prescott filter $(\lambda=1600)$ was applied to the series to extract its trend.

The following is a short description of all variables' sources.

- United States. Bureau of Economic Analysis, NIPA tables. The data can be downloaded from www.bea.doc.gov/bea/dn/nipaweb/AllTables.asp.

The output gap is calculated as the (log) difference between Real Gross Domestic Product and Real Potential Gross Domestic Product, in Billions of Chained 1996 Dollars (source: U.S. Congress, Congressional Budget Office). Inflation is the 4-quarter (log) difference in the Gross Domestic Product Chain-type Price Index, 1996=100, Seasonally Adjusted (source: U.S. Department of Commerce, Bureau of Economic Analysis). The call money rate is the Federal Funds' rate, obtained from IMF's IFS. The fiscal policy indicator was obtained from the sum of Federal and State and Local current surplus or deficit, Billions of Dollars, Seasonally Adjusted Annual Rate (source: National Income and Product Accounts Tables, Tables 3.2 and 3.3).

- Germany, France, United Kingdom and Italy (for output, inflation and interest rate data). IMF's International Financial Statistics (Revenue, Expenditure and Lending minus Repayment, Call Money Rate, Consumer Price Index and Gross Domestic Product); OECD Statistical Compendium (Output Gap, semi-annual observations, linear interpolation was employed to construct the quarterly series).

- Italy, budget series only: The series from IFS lacks a number of observations around 1990. Consequently, a corresponding Bank of Italy's series was employed to integrate 


\section{Graphs}

The plots in the following pages are 95\% confidence bands of the impulse responses from a justidentified SVAR in the output gap (YGAP), inflation (INF), the deviations of the fiscal stance from its H-P filtered trend (FPI), and the call money rate (CMR). Bootstrapping methods (500 simulations) were employed to determine 95\% confidence bands around the orthogonalized response (Choleski factorization of the varcov matrix was applied). INF $\rightarrow$ YGAP, for instance, stands for impulse response of the output gap to a unit shock in the inflation rate.
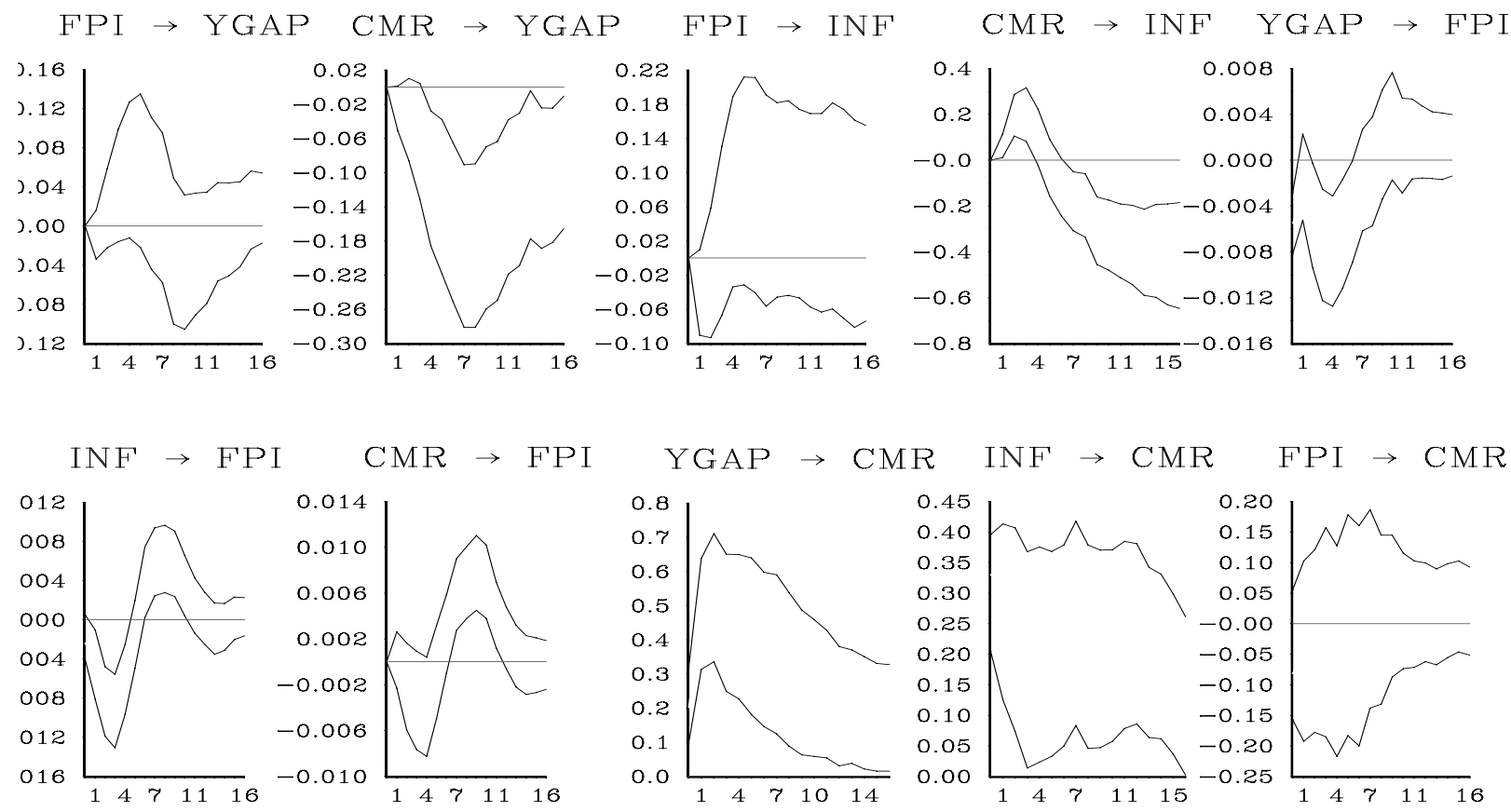

Figure 1. Impulse responses, France 1973Q2-1998Q4. 

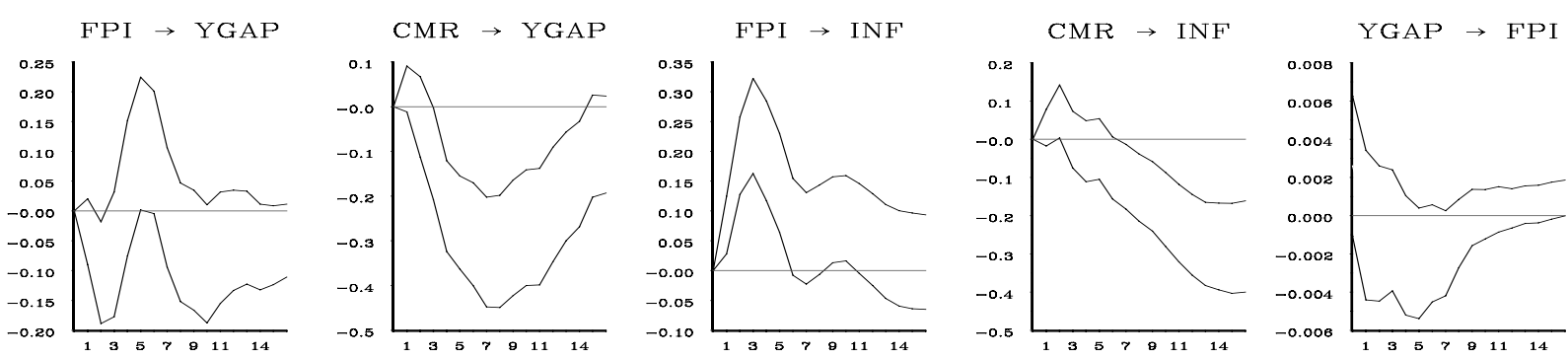

$\mathrm{INF} \rightarrow \mathrm{FPI}$
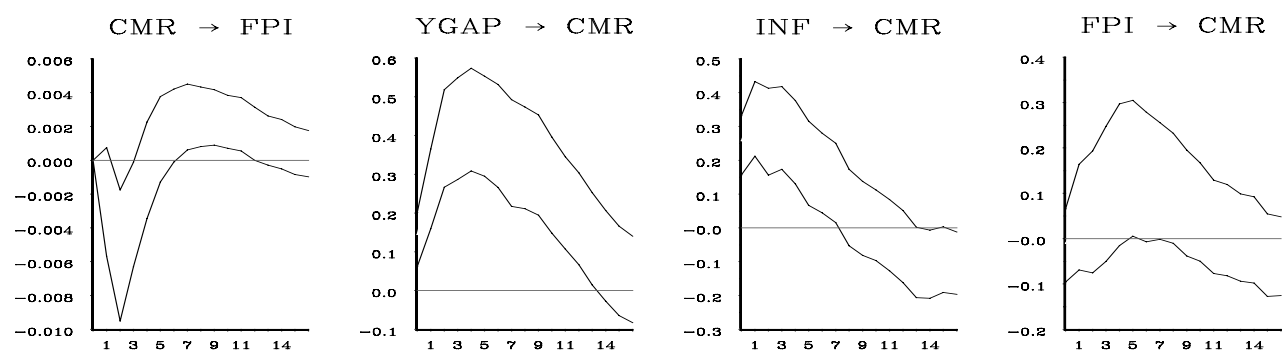

Figure 2. Impulse responses, Germany 1971Q1-1998Q4.
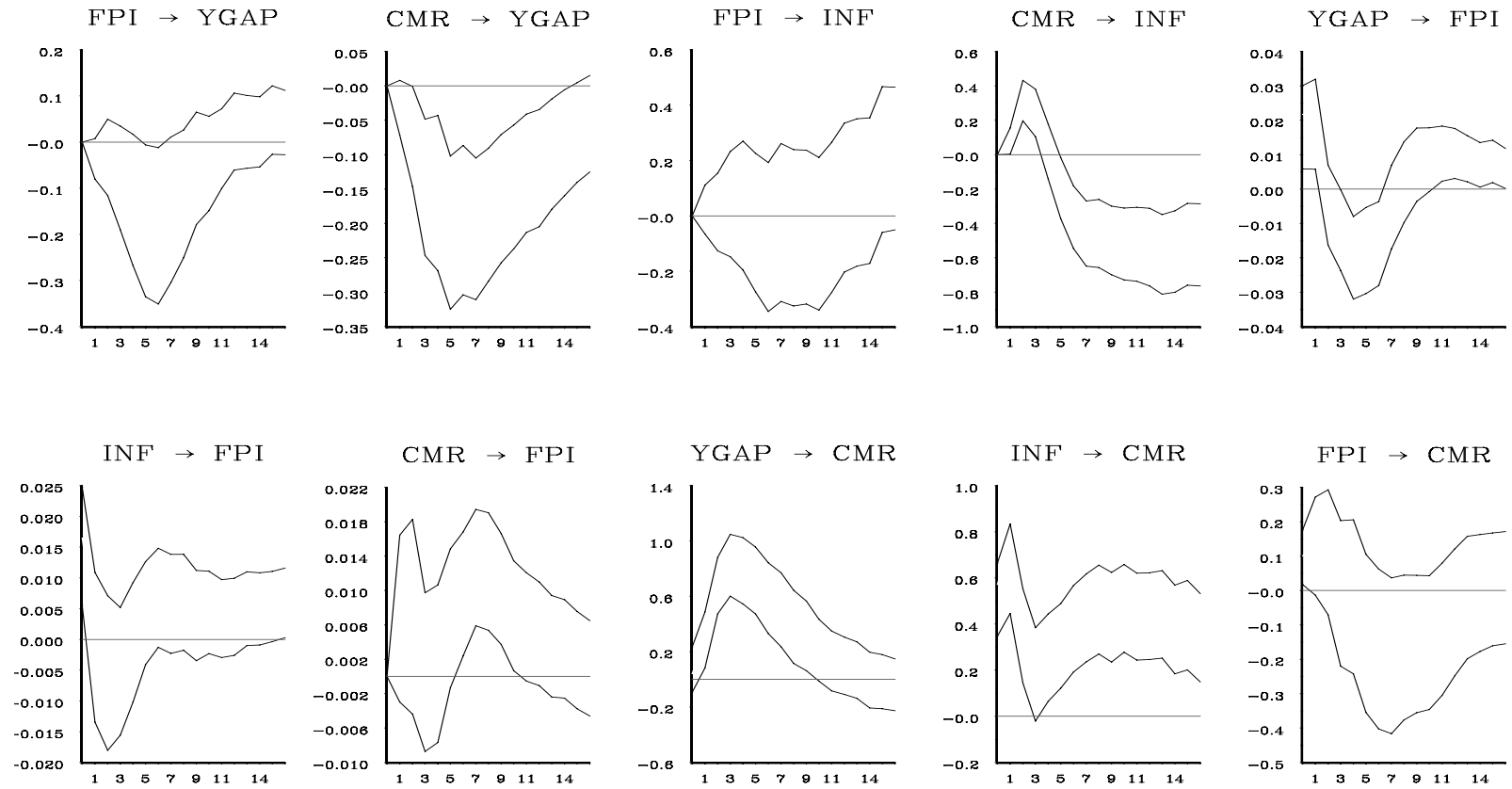

Figure 3. Impulse responses, Italy 1971Q4-1998Q4. 

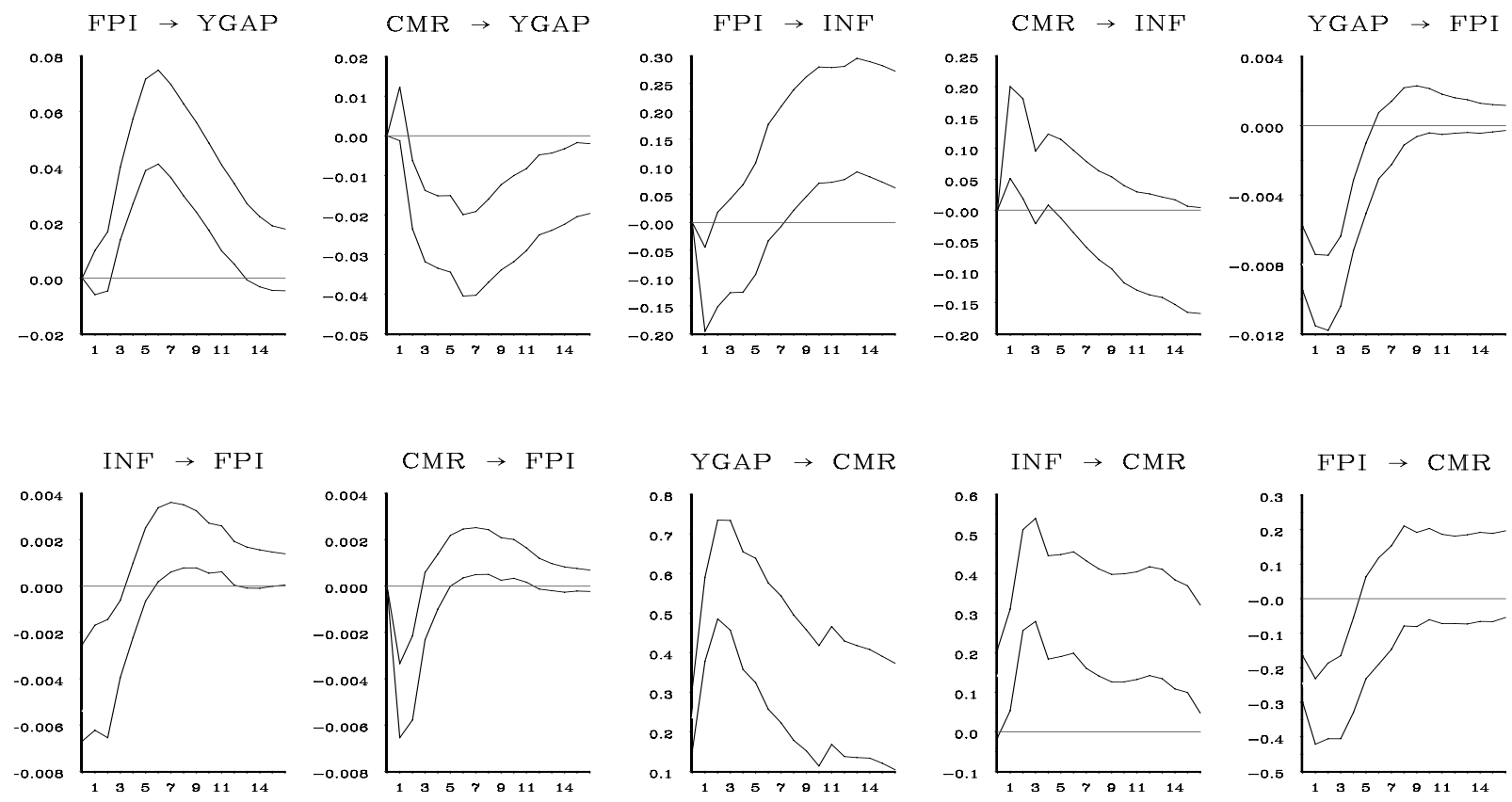

Figure 4. Impulse responses, USA 1955Q1-1998Q4.
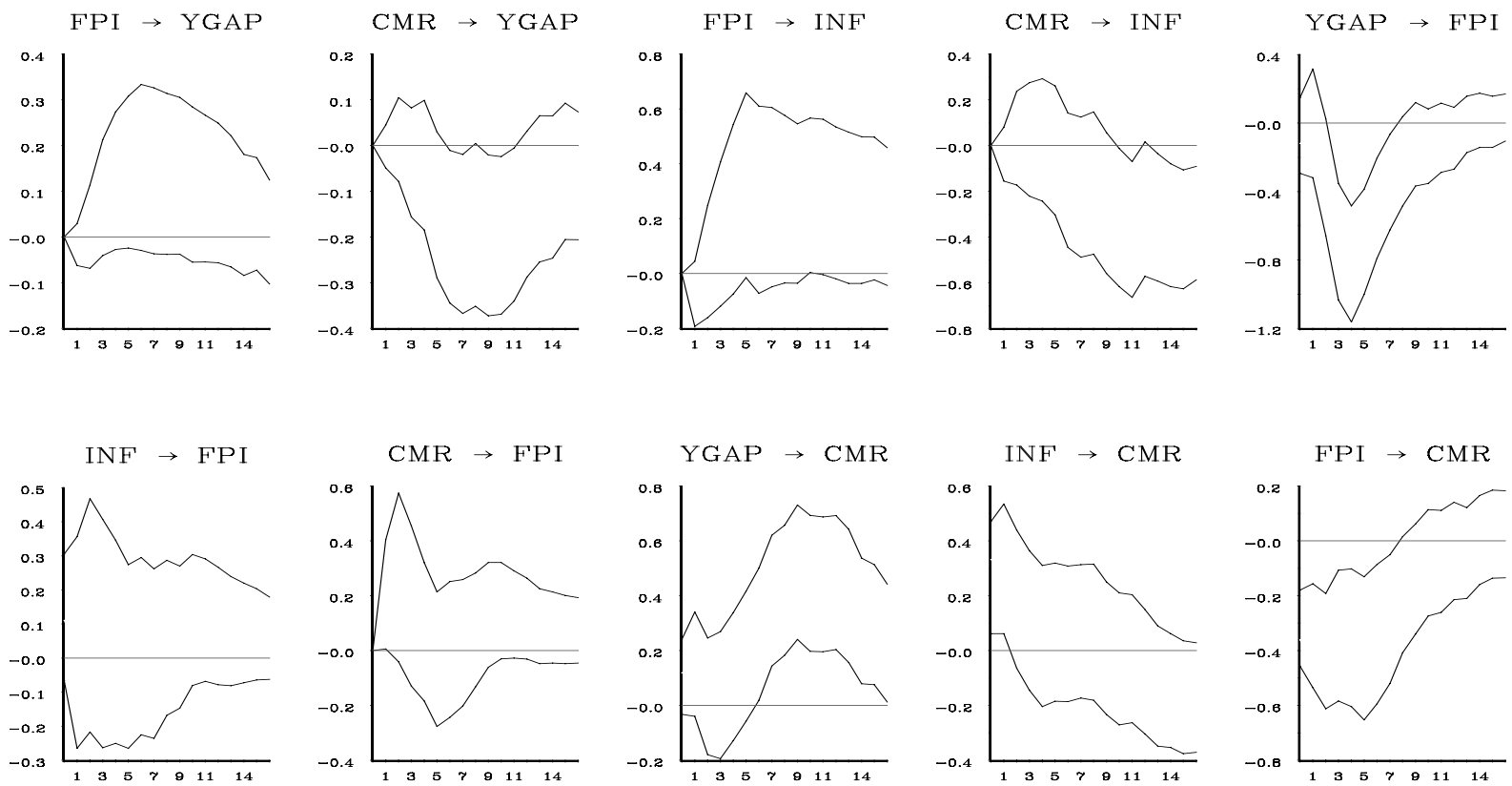

Figure 5. Impulse responses, United Kingdom 1972Q1-1998Q1. 

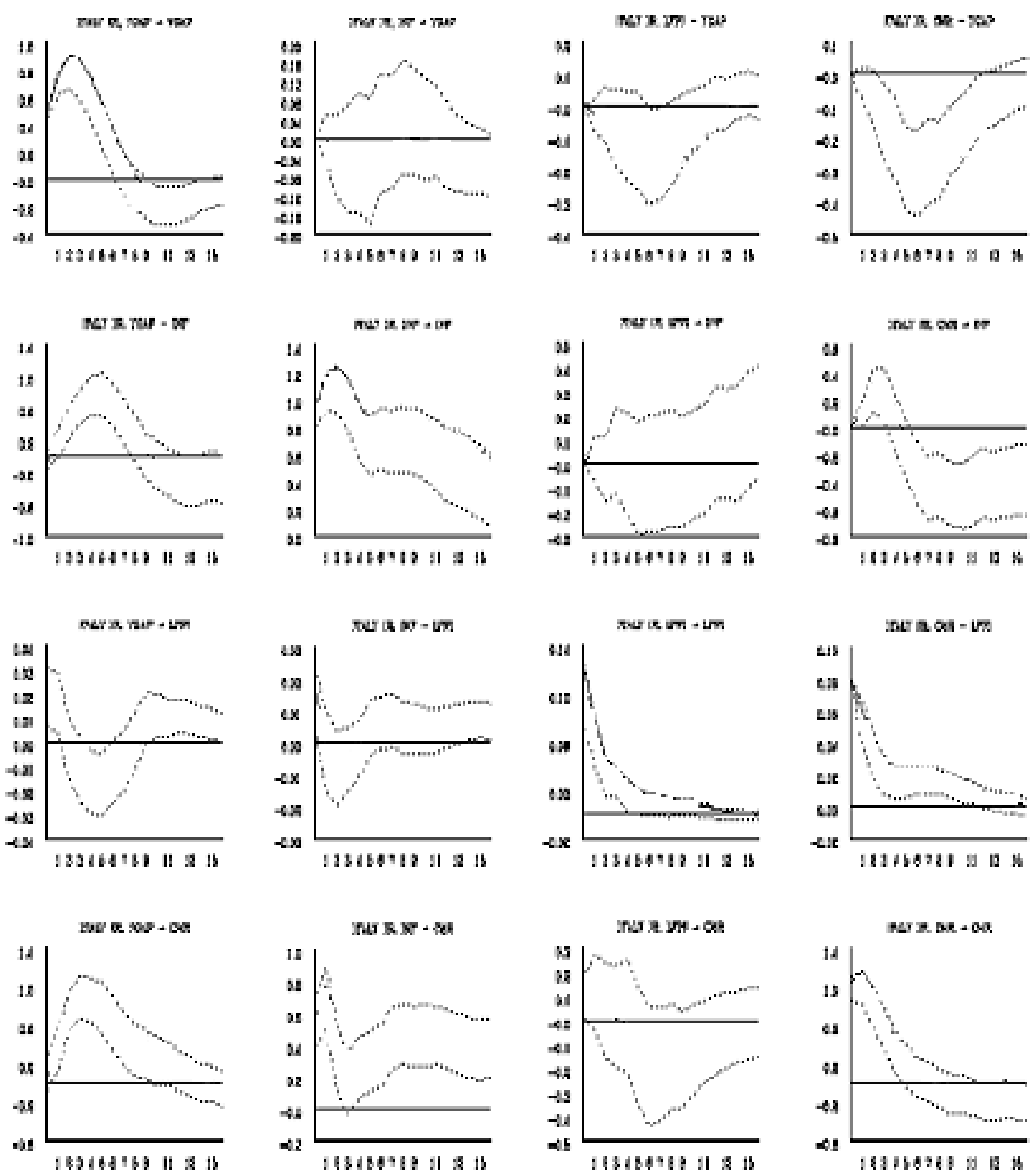

Figure 6. Impulse responses, Italy 1971Q4-1998Q4. It is assumed that a 1\% change in interest rates has a contemporaneous impact of $8 \%$ on the size of the budget deficit. 

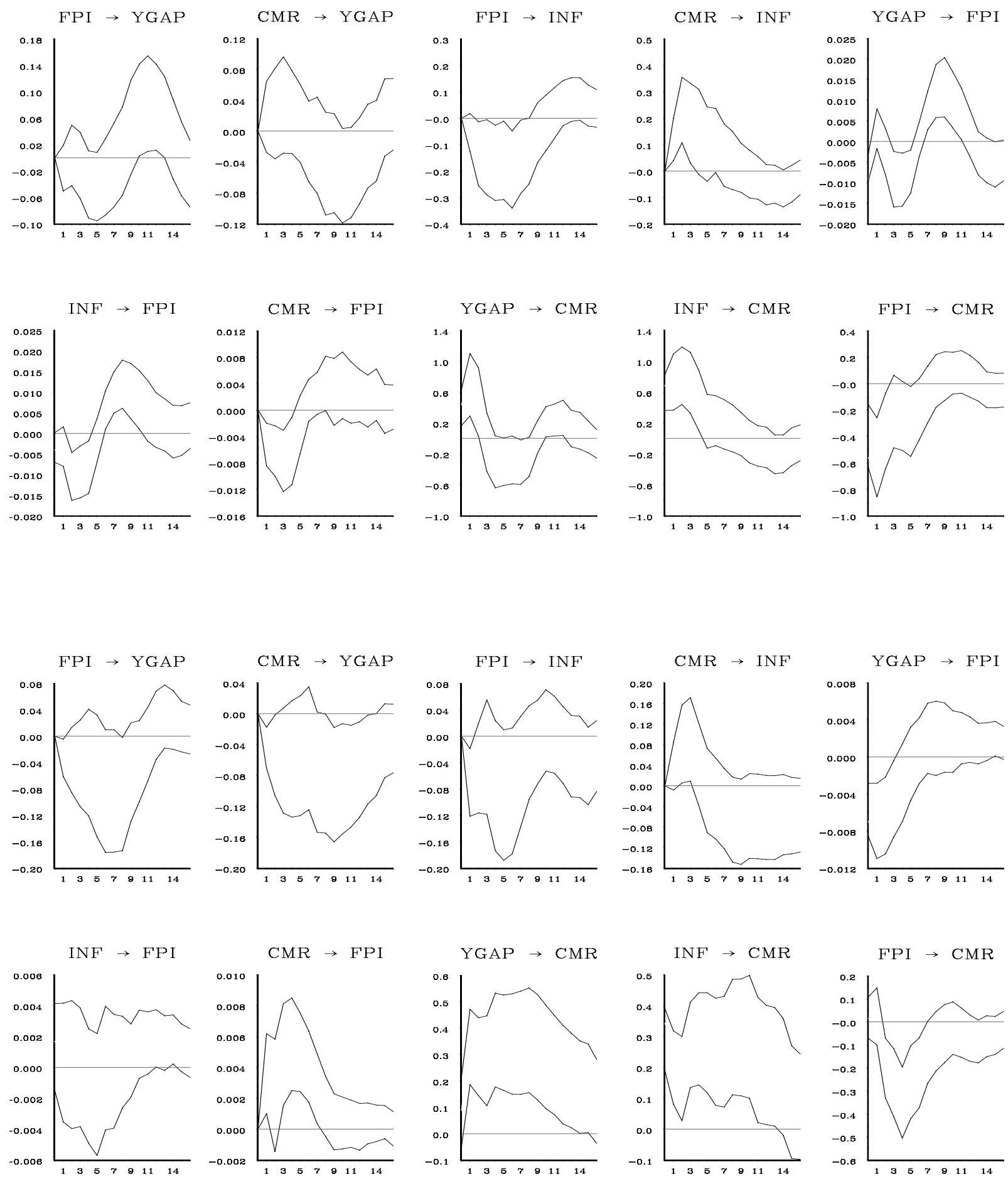

Figure 7. Impulse responses, France: 1973Q2-1982Q2 (top panel) and 1980Q1-1998Q4 (bottom panel). 

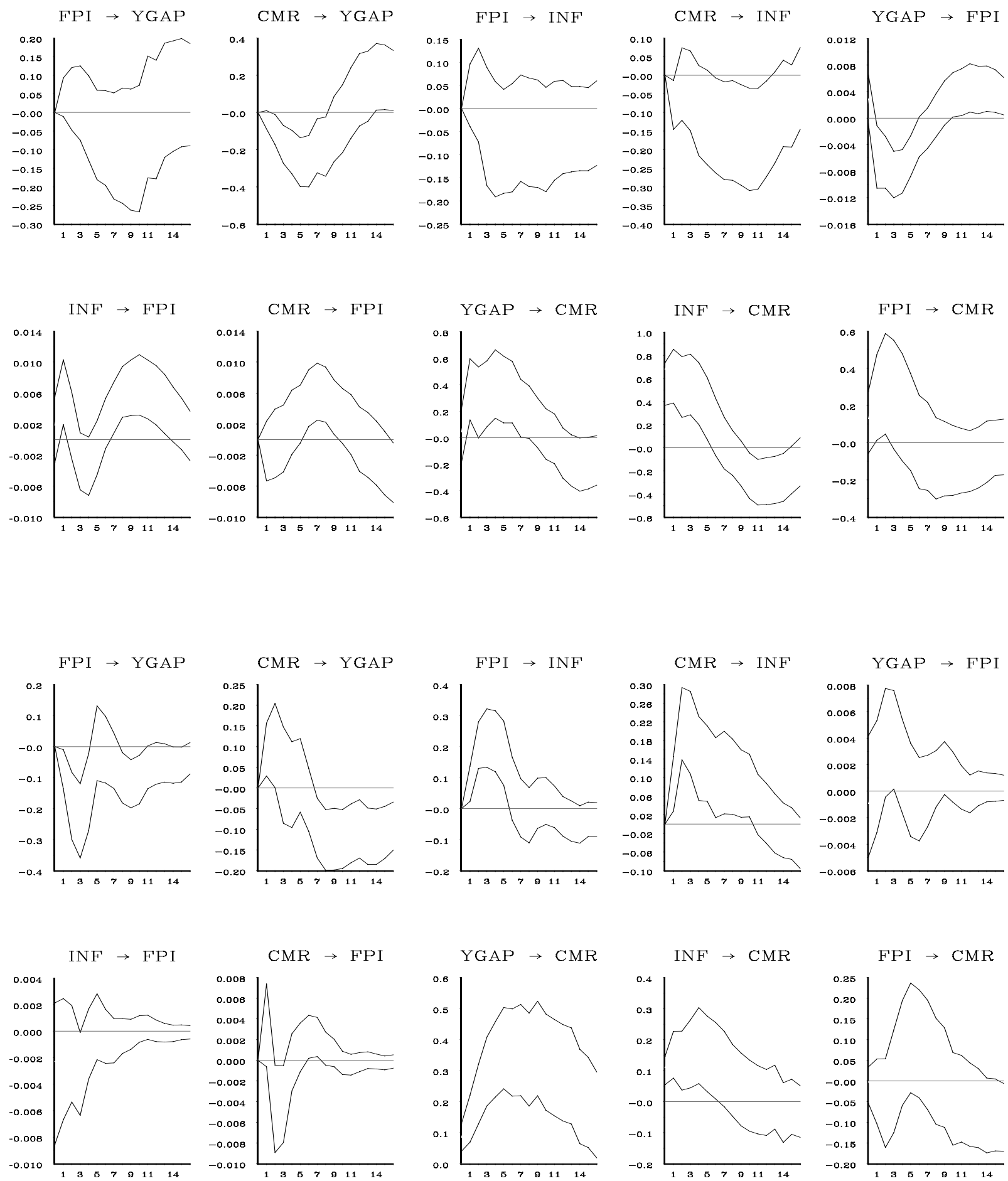

Figure 8. Impulse responses, Germany: 1971Q1-1982Q2 (top panel) and 1980Q1-1998Q4 (bottom panel). 

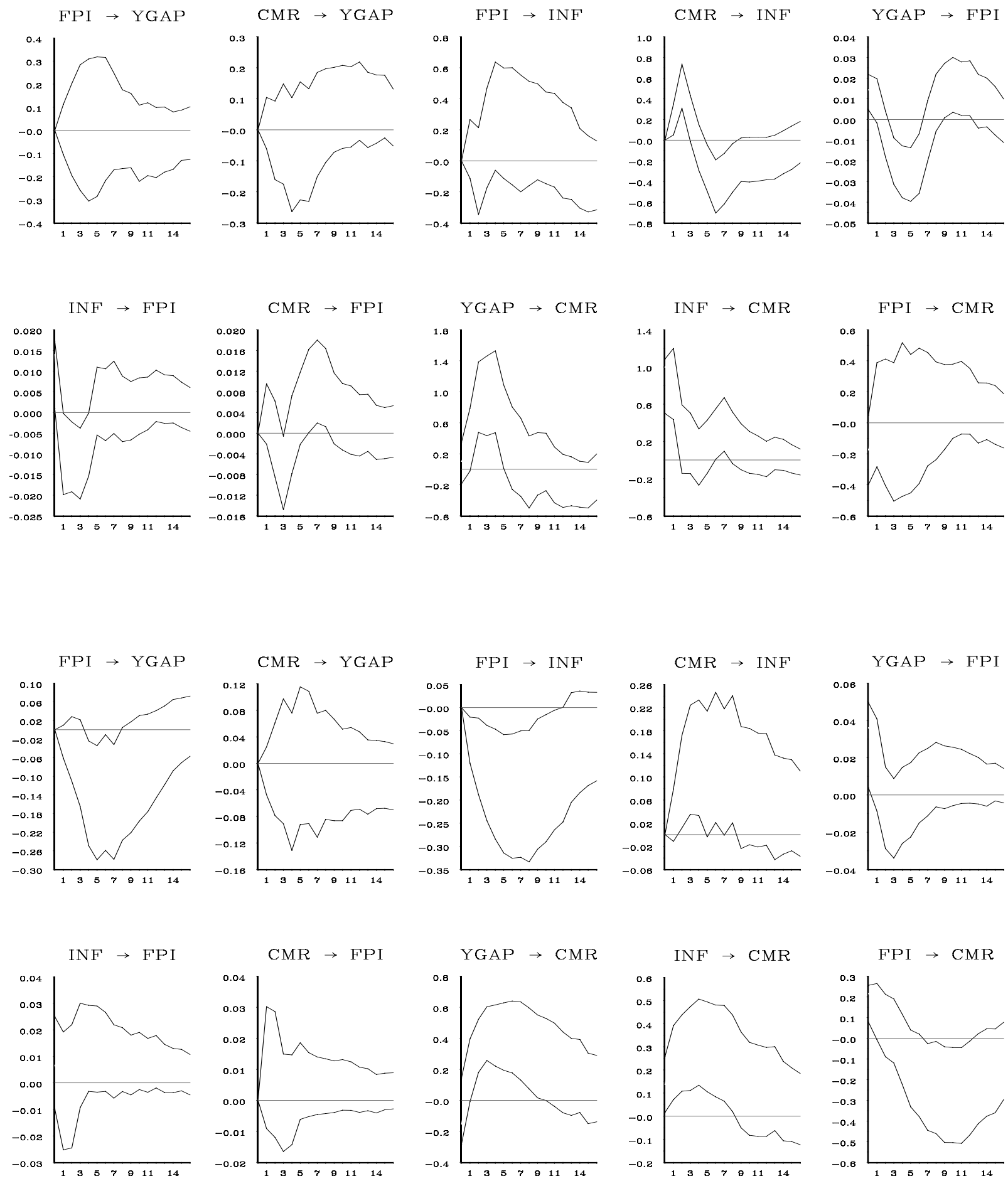

Figure 9. Impulse responses, Italy: 1971Q4-1982Q2 (top panel), and 1983Q1-1998Q4 (bottom panel). 

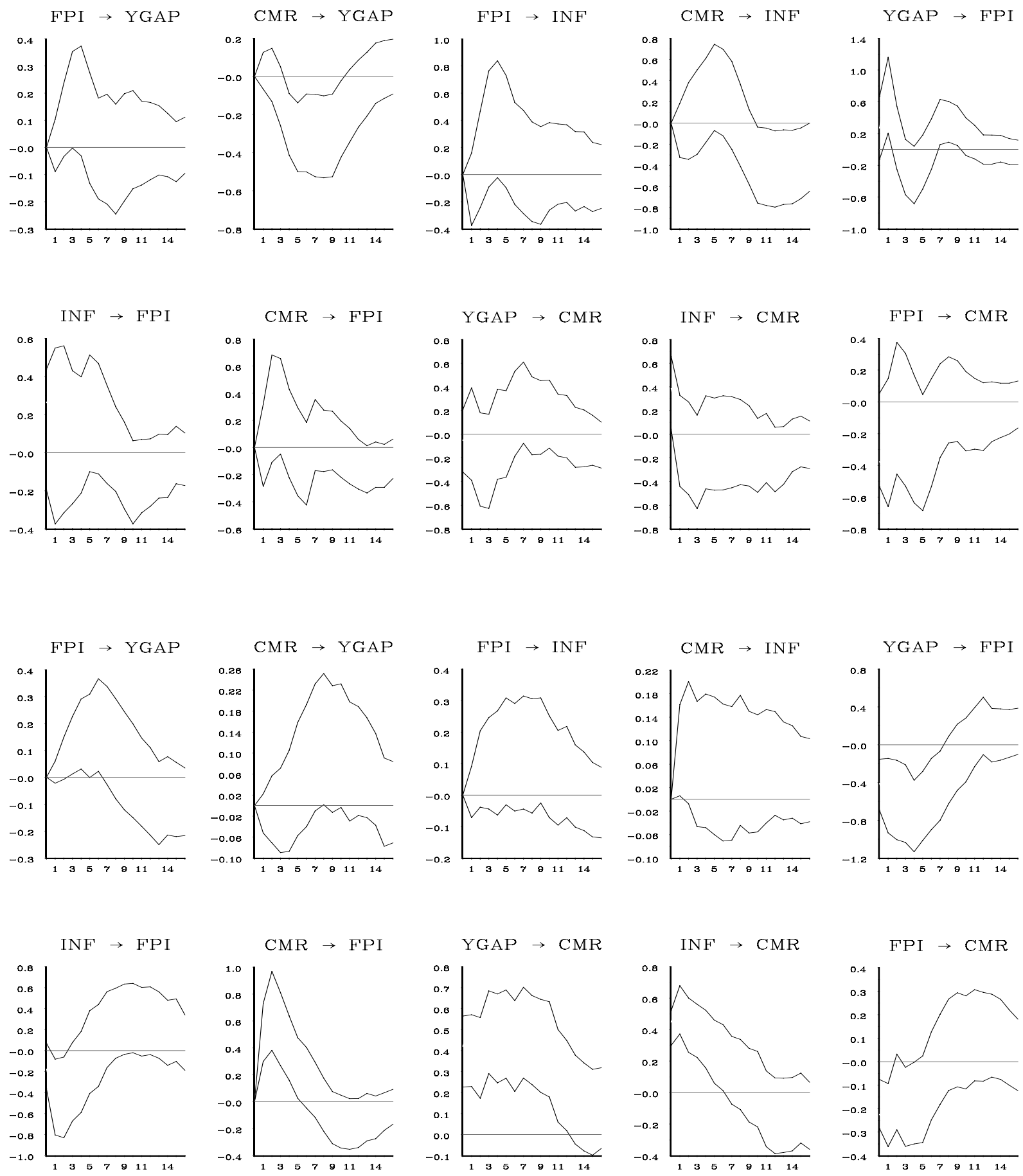

Figure 10. Impulse Responses, United Kingdom: 1972Q1-1982Q2 (top panel), and 1980Q11998Q1 (bottom panel). 

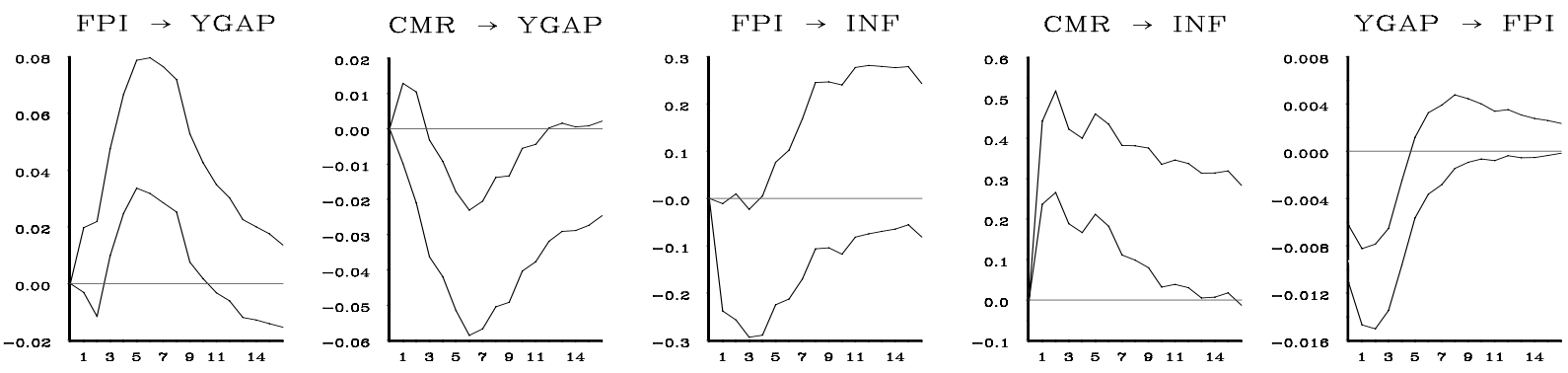

$\mathrm{INF} \rightarrow \mathrm{FPI}$
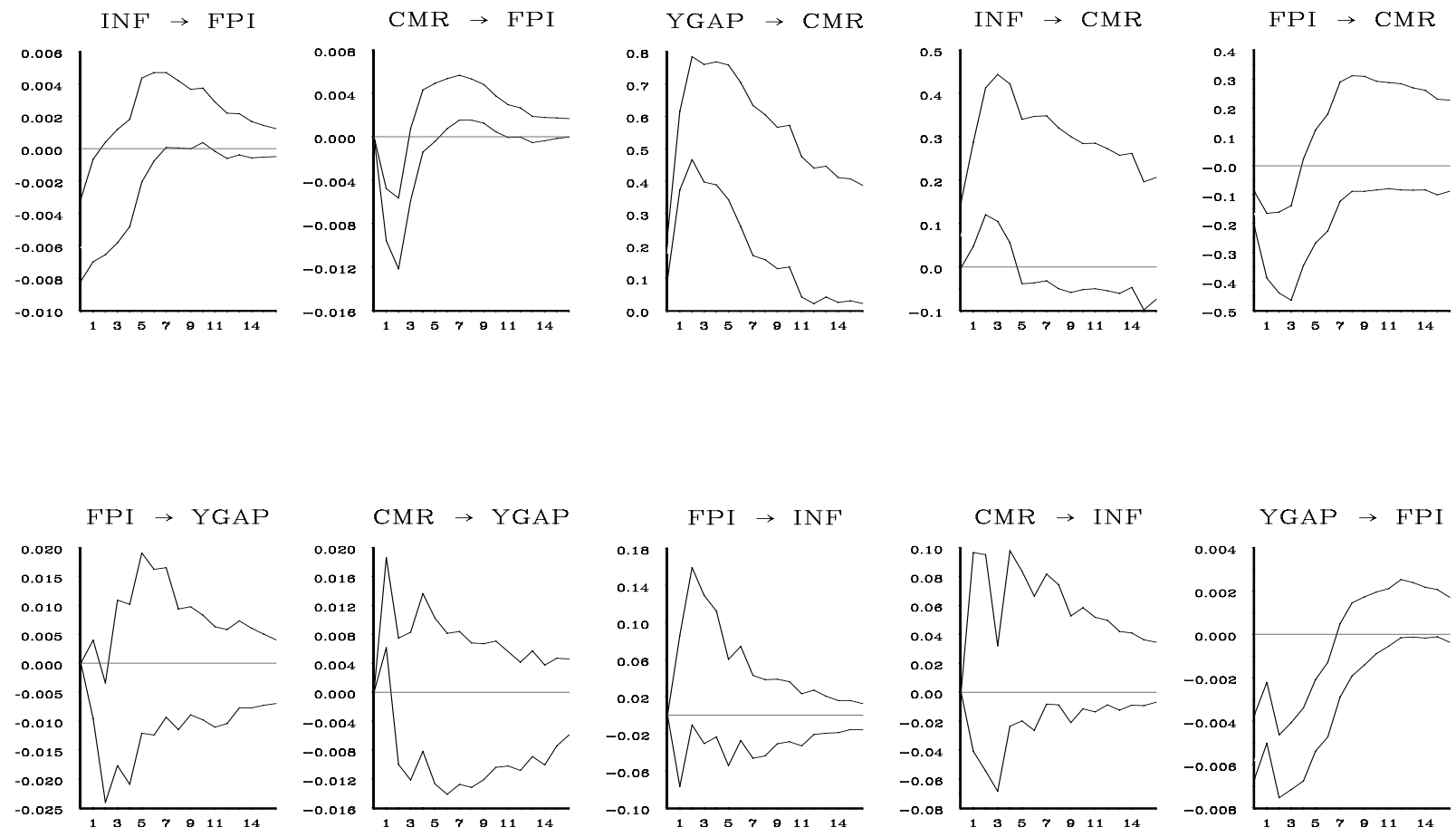

$\mathrm{TNF} \rightarrow \mathrm{FPI}$
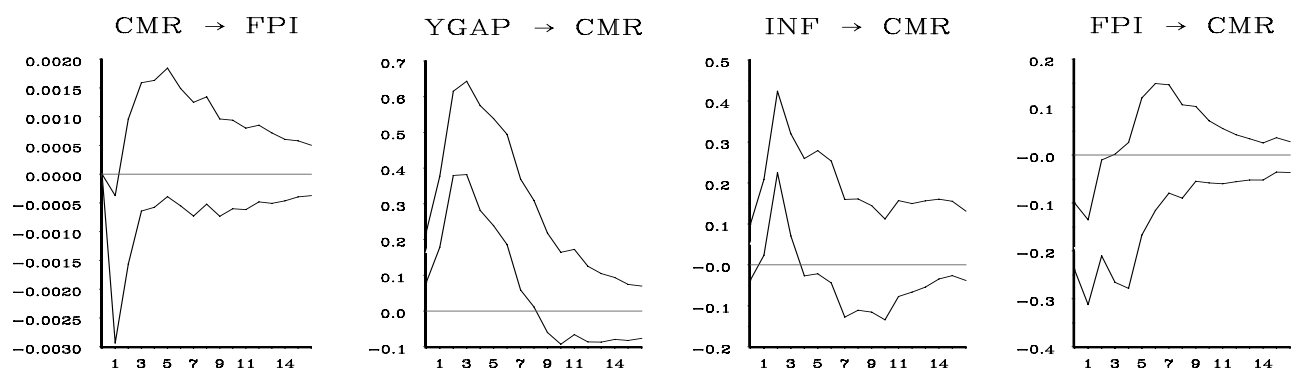

Figure 11. Impulse responses, United States: 1955Q1-1979Q4 (upper panel), and 1980Q11998Q4 (lower panel). 


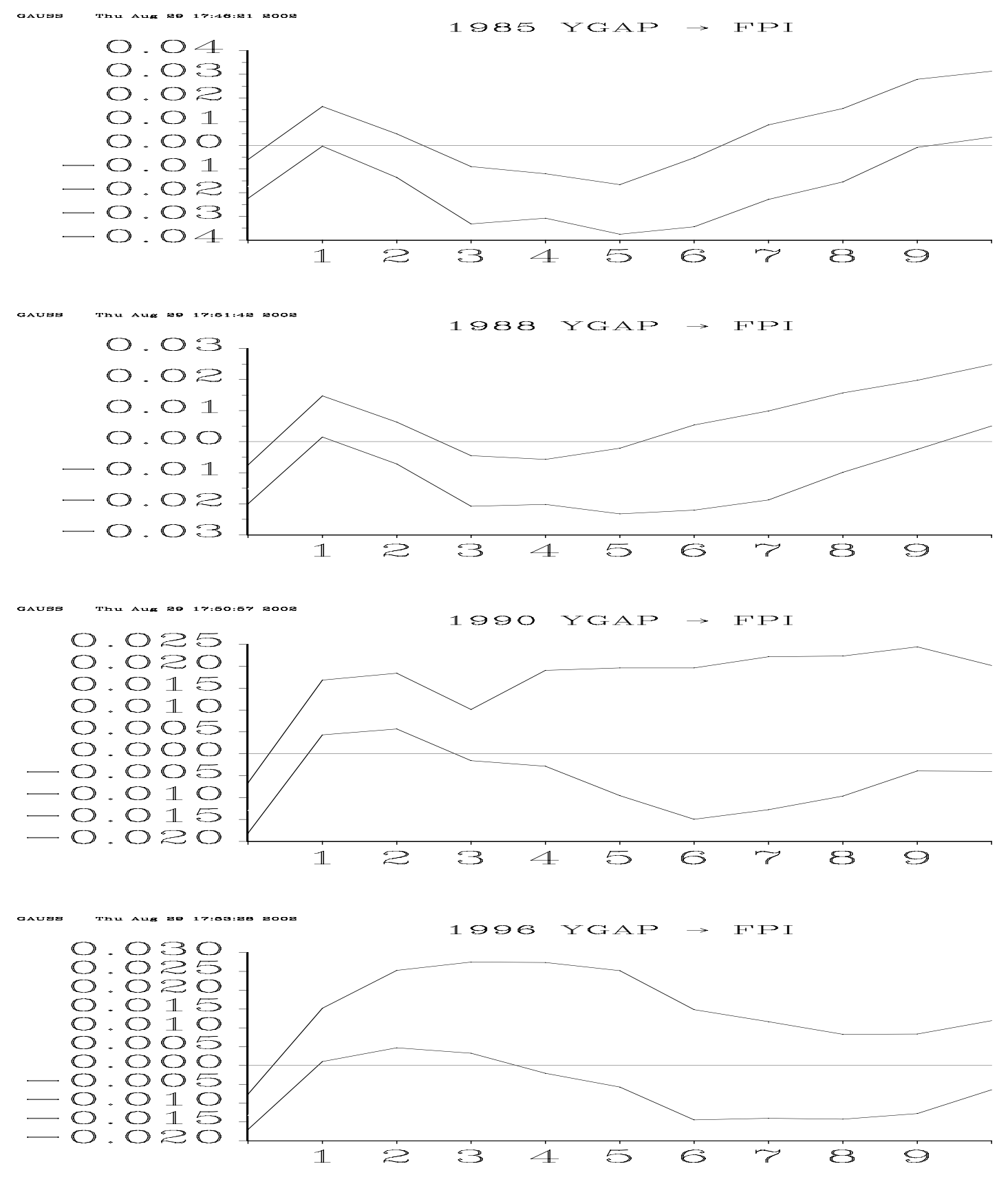

Figure 12. France 1973Q2-1998Q4. Bayesian VAR, impulse responses of the fiscal policy indicator to a shock in the output gap, first quarters of various years. 

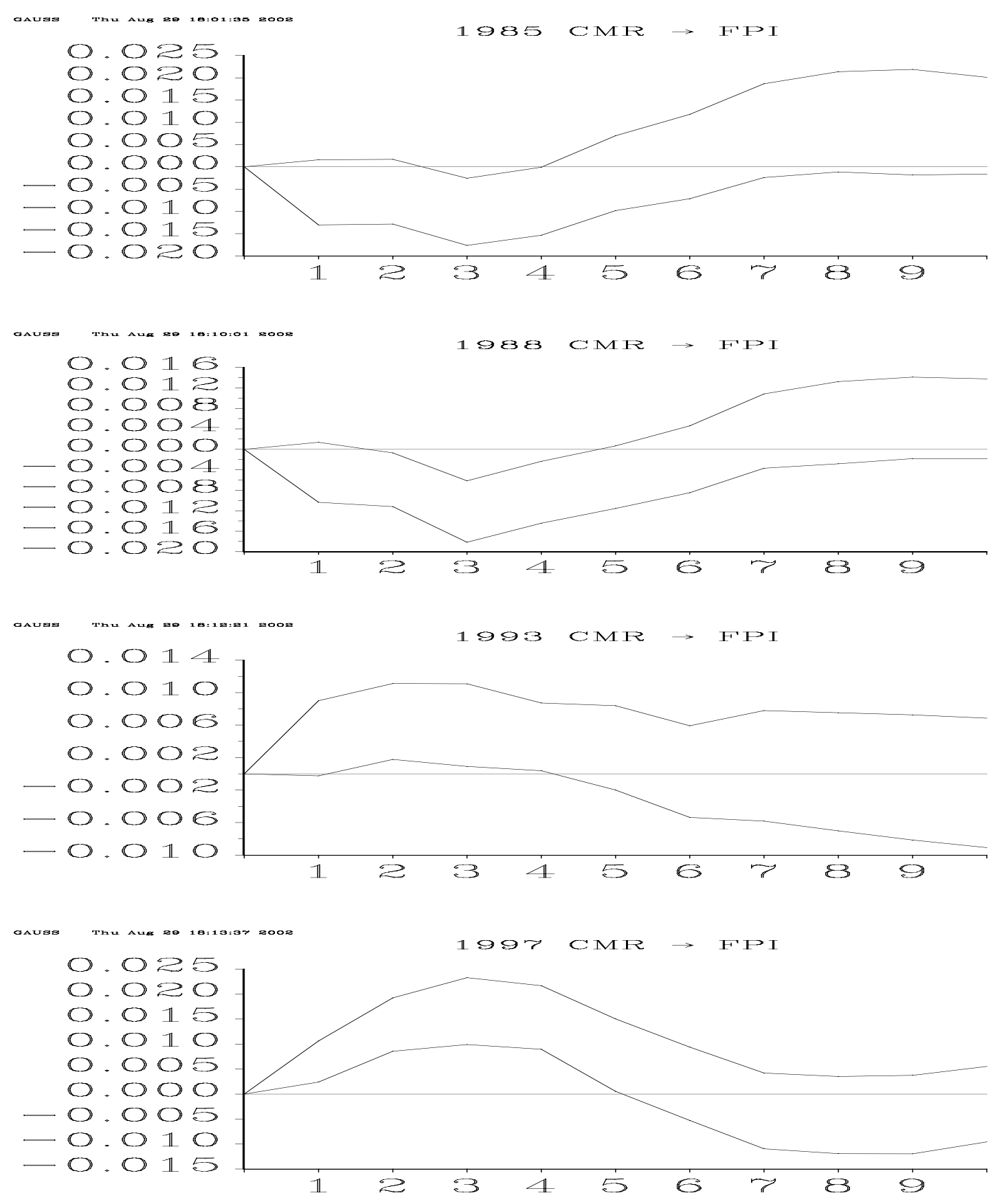

Figure 13. France 1973Q2-1998Q4. Bayesian VAR, impulse responses of the fiscal policy indicator to a shock in the call money rate, first quarters of various years. 

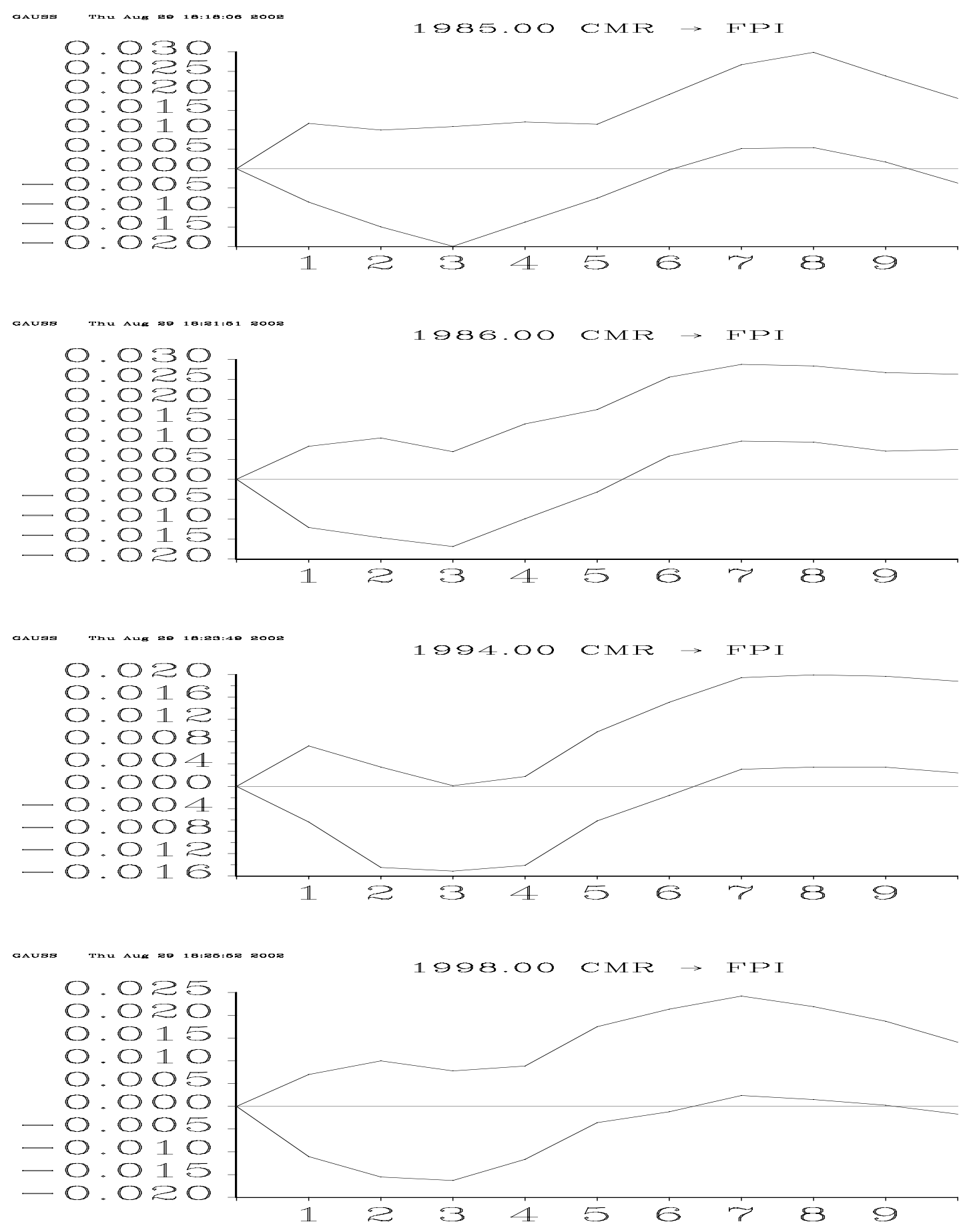

Figure 14. Italy 1971Q4-1998Q4. Bayesian VAR, impulse responses of the fiscal policy indicator to a shock in the call money rate, first quarters of various years. 

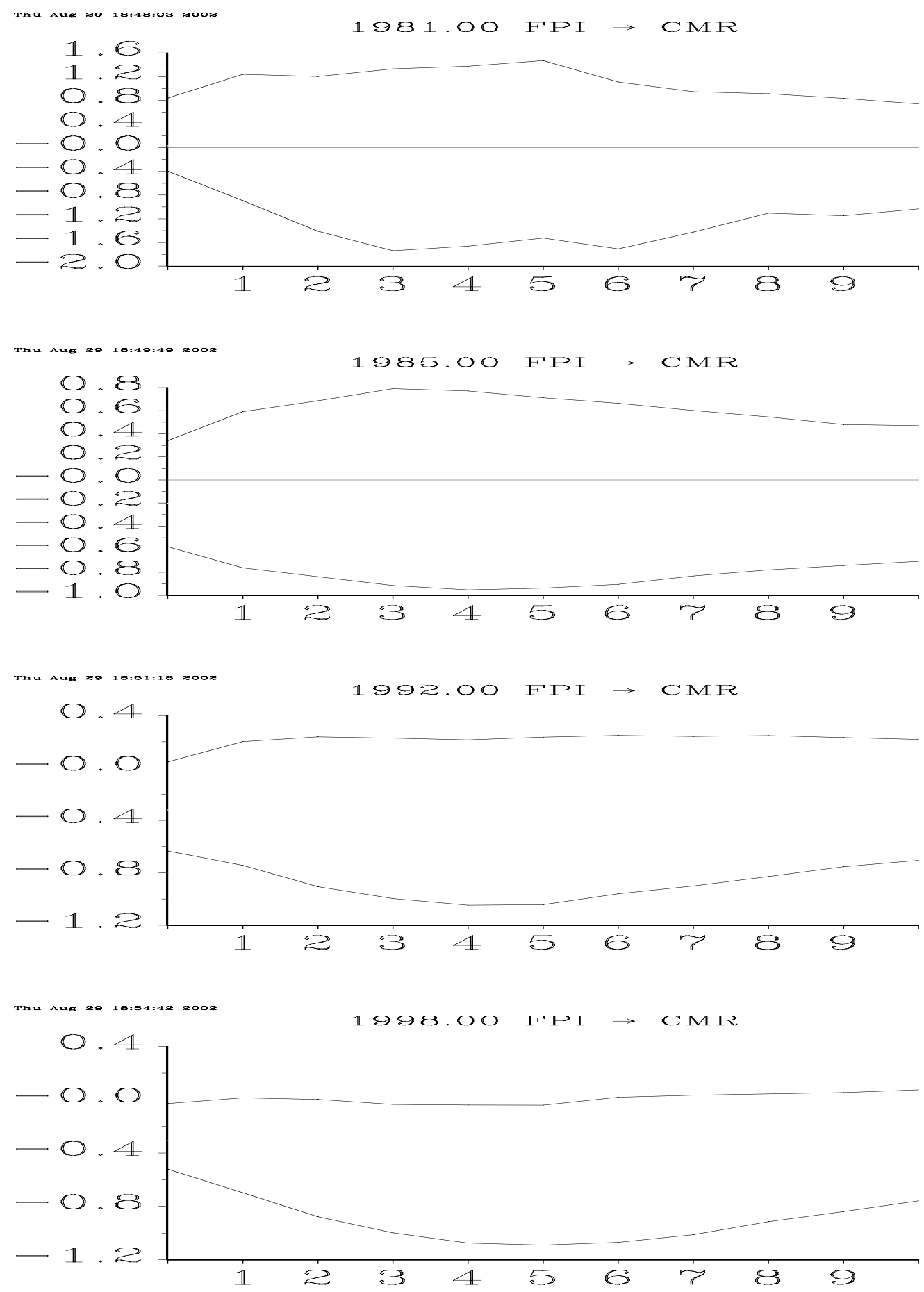

Figure 15. United Kingdom, 1972Q1-1998Q1. Bayesian VAR, impulse responses of the fiscal policy indicator to a shock in the call money rate, first quarters of various years. 

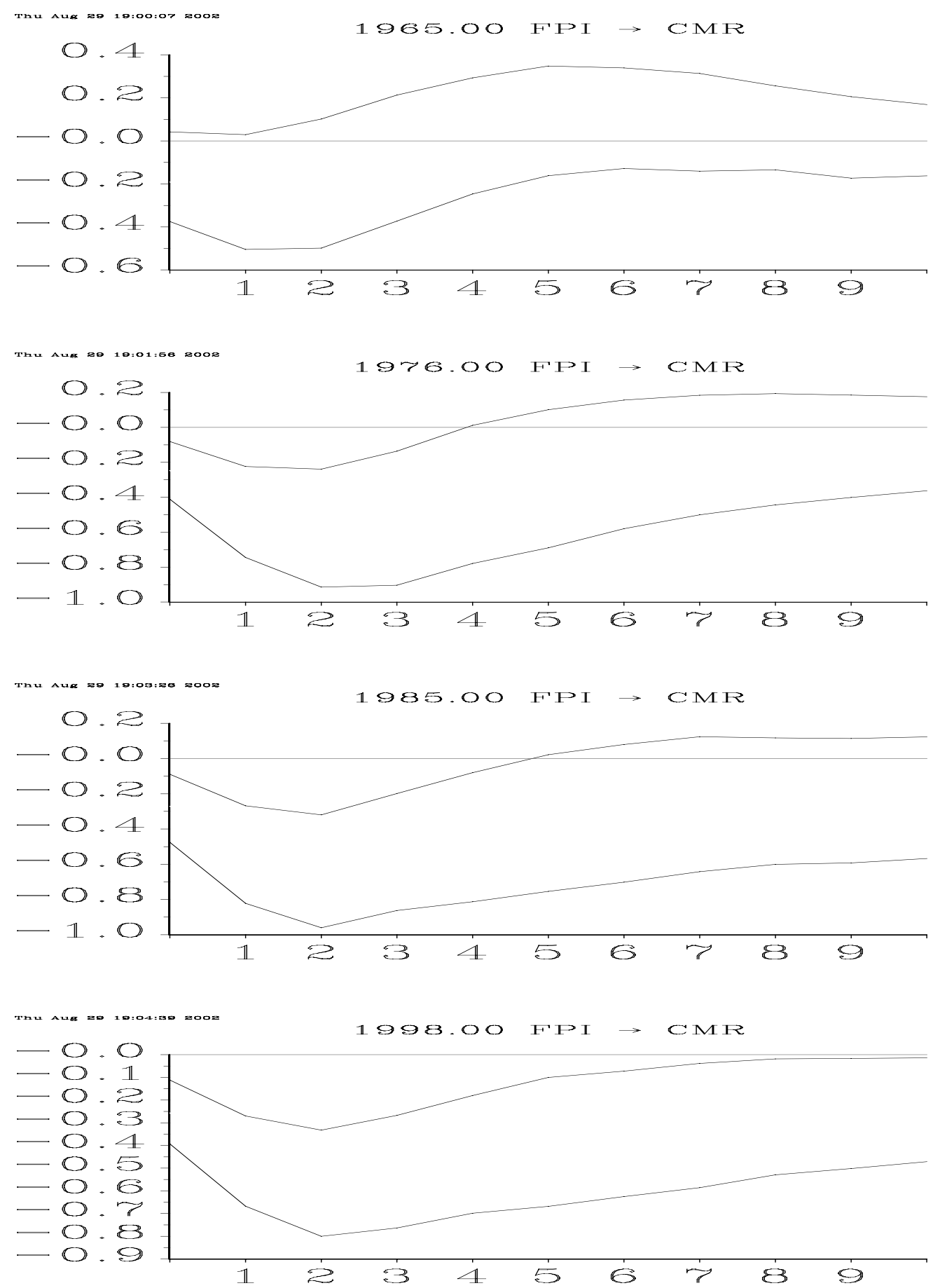

Figure 16. USA, 1957Q1-1998Q4. Bayesian VAR, impulse responses of the fiscal policy indicator to a shock in the call money rate, first quarters of various years. 